\title{
Free Vibration of Axially Loaded Multi-Cracked Beams Using the Transfer Matrix Method
}

\author{
Yousef S. Al Rjoub and Azhar G. Hamad \\ Civil Engineering Department, Jordan University of Science and Technology, P. O. Box 3030, Irbid, 22110, Jordan.
}

(Received 29 August 2016; accepted 26 April 2017)

In this paper, an analytical method is developed to study the free vibration of multi-cracked, axially loaded beams with differing boundary conditions, namely, hinged-hinged, clamped-clamped, clamped-hinged, and clamped-free. The cracked beam system is modelled as a number of beam segments connected by massless rotational springs with sectional flexibility. Each segment is assumed to obey the Euler-Bernoulli beam theory. The characteristic equation of the cracked beam with differing boundary conditions, which is a function of the natural frequency, sizes and location of the cracks, and the physical parameters of the beam, as well as the corresponding mode shapes, is derived using a simple transfer matrix method. In this paper, a detailed parametric study is conducted to show the effects of cracks and axial load on vibrational properties of the cracked beam. The results obtained in this study agree well with analytical results available in the literature.

\section{INTRODUCTION AND LITERATURE REVIEW}

Beams are one of the primary structural elements that are widely used in various aeronautical, civil, and mechanical engineering fields. The response of structures under service loads is one way of evaluating structural systems. Structures, such as bridges, may experience fatigue or overloading, which may cause cracking. These cracks change the dynamic properties of the structure, such as natural frequencies and corresponding mode shapes. Much research has been done to study the effect of cracks on the vibrational properties of structures.

In recent decades, experimental research on the effects of crack and damage on the safety of structures has had the attention of specialists in this area. Liebowitz and Claus, some of the pathfinders in this area, studied the load capacity of columns with cracks and suggested a failure gauge based on a stress concentration factor. ${ }^{1}$ A state-of-the-art review was presented by Dimarogonas for papers published between 1971 and 1995 on the dynamic response of beams and rotor structures with cracks. ${ }^{2}$ The reviewed papers were classified into three categories, according to the way the problem was addressed: the equivalent reduced section method, the continuous cracked beam method, and the local flexibility method.

Kirmsher and Thomson both used the equivalent reduced section method. ${ }^{3,4}$ A local bending moment and a reduced section are used to simulate cracks. This method is considered to be the first attempt to measure the stiffness reduction in a cracked region. The theory of cracks and exact numerical simulation methods were not available at that time (1943), so the stiffness reduction due to a crack was estimated by experiment.

Christides and Barr used the continuous cracked beam method and found that the existence of cracks would lead to material changes in strain distributions and stresses in the cracked region. ${ }^{5,6}$ Near the end of a crack, a large stress concentration appeared. The stresses over the cross-section were distributed nonlinearly. The changes in stress and strain distribution in the cracked region were approximated by an un- known function, which had a maximum value at the tip of the cracks. Although the boundary conditions and some elements of the stress distribution in the cracked region were simulated by the function, the discontinuity in the stress distribution was an obvious weakness of the function, as stress and strain should distribute continuously throughout a structure. Zheng and Ji showed that the stress distribution in the vicinity of an abrupt change of cross-section remains continuous by using a fine meshed finite element model. ${ }^{7}$ In 1998, Chondros et al. modelled the cracked area as a continuous flexible system. ${ }^{8}$ This model gave a better approximation of the stress and displacement distributions.

In this paper, the analytical approach was based on the concept of the local flexibility method. This method considered the cracked beam as a number of beam segments with the same properties, connected by massless rotational springs at the cracked sections. In 1976, Dimarogonas estimated the local flexibility of the cracked region and determined the stiffness of the massless springs, which represented the cracks. ${ }^{9}$ Local flexibility was used to estimate the crack Stress Intensity Factor (SIF). SIF is an important concept in fracture mechanics, representing the stress intensity near the tip of a crack due to remote loads or residual stresses. Castigliano's theorem and fracture mechanics were used by Liebowitz and Claus Jr., Liebowitz et al., ${ }^{10}$ and Okamura et al. ${ }^{11}$ to compute the flexibility of the cracked region of a uniform beam with a transverse surface crack, which is a function of the ratio of crack depth to the height of the cross-section. The function was obtained experimentally, according to the measurements provided by Brown and Srawley. ${ }^{12}$ This factor can also be obtained in Tada et al.'s handbook. ${ }^{13}$ Yoon, et al. studied the dynamic behaviour of a simply-supported Euler-Bernoulli beam with double cracks, both analytically and experimentally. ${ }^{14}$ Hamilton's principle was used to derive the equation of motion. The influence of the crack position and its depth on the natural frequencies and corresponding mode shapes was studied. A simplified method was used by Fernandez-Saez et al. to evaluate the natural frequencies of a simply-supported Euler-Bernoulli beam with one 
transverse crack at an arbitrary location. ${ }^{15}$ The cracked beam was divided into $n$ beam segments with $n-1$ cracks and the deflection of each segment was defined as that of an uncracked beam plus a polynomial function, which included four unknown coefficients in each segment. An exact theoretical solution for the natural frequency of a beam with a single crack was obtained by Fernandez-Saez's method. For a cracked beam with other boundary conditions, Fernandez-Saez and Navarro used a flexibility influence function to express the mode shape of a cracked beam. ${ }^{16}$ Fernandez-Saez's method was further developed by Zhong and Oyadiji to study the vibrational frequencies of a cracked beam with a stationary concentrated mass. ${ }^{17}$ Loya et al. and Kato calculated the natural frequency of a cracked Timoshenko beam using a first-order solution. ${ }^{18,19}$ The mode shape function and rotation function of a cracked beam were slightly different than those of an uncracked beam. The analytical solution of a cracked beam became more complicated as the number of cracks increased. Jang and Bert analysed free vibration of stepped beams with different boundary conditions. ${ }^{20}$ Naguleswaran studied the vibration of a stepped beam, including axial deformations. ${ }^{21}$ Aydin determined the natural frequencies and corresponding mode shapes of cracked beams, including the effects of axial loading, analytically. ${ }^{22}$ The effects of cracks and axial loading on the vibrational properties of cracked beam were investigated. Crack effects on the buckling load were also studied. Zheng and Ji used an approximate method to determine the stiffness and natural frequencies of a cracked beam. ${ }^{23}$ An analytical model was developed by Gomes and Almeida to study the dynamic behaviour of a single, cracked, simply-supported, clamped-free beam. ${ }^{24}$ The effects of bending, axial stiffness, rotational inertia, shear deformation, and coupling of the last two terms were included in the analysis. Ostachowicz and Krawczuk analysed the effect of cracks on the natural frequencies of a cantilever beam. ${ }^{25}$ Also, wavelet transform theory and the transfer matrix method were used to calculate the characteristic equation and corresponding mode shapes of cracked beams.

The transfer matrix method (TMM) is a prevalent and efficient tool for free vibration analysis of beams with nonuniform mechanical properties. This method was first introduced by Pestel and Leckie, and used by other researchers. ${ }^{26-29}$ Modified transfer matrix methods were also developed by Liu and Huang, and Aleyaasin et al. to study the dynamic behaviour of beams with various attachments. ${ }^{30,31}$ Studies on the bending vibration of edge-cracked beams were presented mostly for uniform beams with only one or, at most, two cracks. There are a few studies on the vibration of non-uniform beams with multiple cracks. Attar studied the free vibration of a cracked, stepped Euler- Bernoulli beam using the simple transfer matrix method. ${ }^{32}$ Attar also developed a new method to solve the inverse problem of determining the location and depth of Euler-Bernoulli beams with multiple cracks. Nandwana and Maiti used the transfer matrix method to detect cracked regions in a stepped cantilever beam. ${ }^{33}$ Khiem and Lien used the TMM to study the free and forced vibrations of multi-crack beams. ${ }^{34,35}$

Other researchers solved the problem using the finite element method. The natural frequencies and corresponding mode shapes were obtained by Zheng and Kessissoglou using the finite element method. ${ }^{36}$ The vibration and stability anal- yses of a multi-crack beam under compressive axial loading were studied by Kirsa using the finite element and componentmode synthesis methods. ${ }^{37}$ The effects of axial loads and crack locations on the natural frequencies and corresponding mode shapes were investigated. Also, the effects of crack ratios and locations on the buckling load were studied. Mode shapes of a cracked three-dimensional beam were analysed by Nguyen using the finite element method. ${ }^{38}$ The coupling effects of horizontal bending and vertical bending vibrations on the mode shapes were investigated.

To the authors' knowledge, there is no previous detailed study in the open literature showing the effects of four cracks on dynamic behaviour of axially loaded beams. In this paper, the dynamic behaviour of a cracked beam under axial loading with an arbitrary number of transverse cracks and different boundary conditions will be investigated. Accordingly, the natural frequencies and the corresponding mode shapes of the beam will be obtained using a simple transfer matrix method and compared to those results available in literature.

\section{THEORETICAL MODEL}

Consider a multi-cracked beam with linear and rotational springs at both ends $\left(K_{1}, K_{R 1}, K_{2}\right.$, and $\left.K_{R 2}\right)$ which represent the general boundary conditions, with length $l$, cross sectional area of width $b$ and height $h$, and a number of singlesided open cracks located at points $x_{c 1}, x_{c 2}, \ldots, x_{c i}$ with sizes $a_{c, 1}, a_{c, 2}, \ldots, a_{c, i}$, respectively, as shown in Fig. 1 . It is assumed that the beam is an Euler-Bernoulli beam with $n$ segments joined by massless rotational springs, as shown in Fig. 2. The governing differential equation of an intact EulerBernoulli beam under axial loading $(N)$ can be written as:

$$
E I \frac{\partial^{4} y(x, t)}{\partial x^{4}}+\rho A \frac{\partial^{2} y(x, t)}{\partial t^{2}} \pm N \frac{\partial^{2} y(x, t)}{\partial x^{2}}=0
$$

where $E, I, \rho, A, y(x, t)$, and the double sign \pm are Young's modulus, moment of inertia, density, cross sectional area, the transverse deflection of the beam, and + for compressive force and - for tensile force, respectively.

The cracked element, as shown in Fig. 3, is loaded with axial force $P_{1}$, and bending moment $P_{6}$, only. Using Castigliano's theorem, the additional displacement caused by the crack is given as:

$$
u_{i}=\frac{\partial U}{\partial P_{i}}=\frac{\partial}{\partial P_{i}}\left[\int_{A_{c}} J d A\right] ;
$$

where $U, A_{c}$, and $J$ are the strain energy due to the crack, the crack section, and the strain energy density function, respectively.

The strain energy density function can be expressed according to Tada et al. for plane stress as: ${ }^{13}$

$$
\begin{array}{r}
J=\left(\frac{1-\nu^{2}}{E}\right)\left[\left(\sum_{i=1}^{6} K_{\mathrm{I} i}\right)^{2}+\left(\sum_{i=1}^{6} K_{\mathrm{II} i}\right)^{2}+\right. \\
\left.(1+\nu)\left(\sum_{i=1}^{6} K_{\mathrm{III} i}\right)^{2}\right]
\end{array}
$$

where $\nu$ is the Poisson's ratio and $K_{\mathrm{I} i}, K_{\mathrm{II} i}, K_{\mathrm{III} i}$ are the crack stress intensity factors for opening mode, shearing mode, and tearing mode, respectively. 


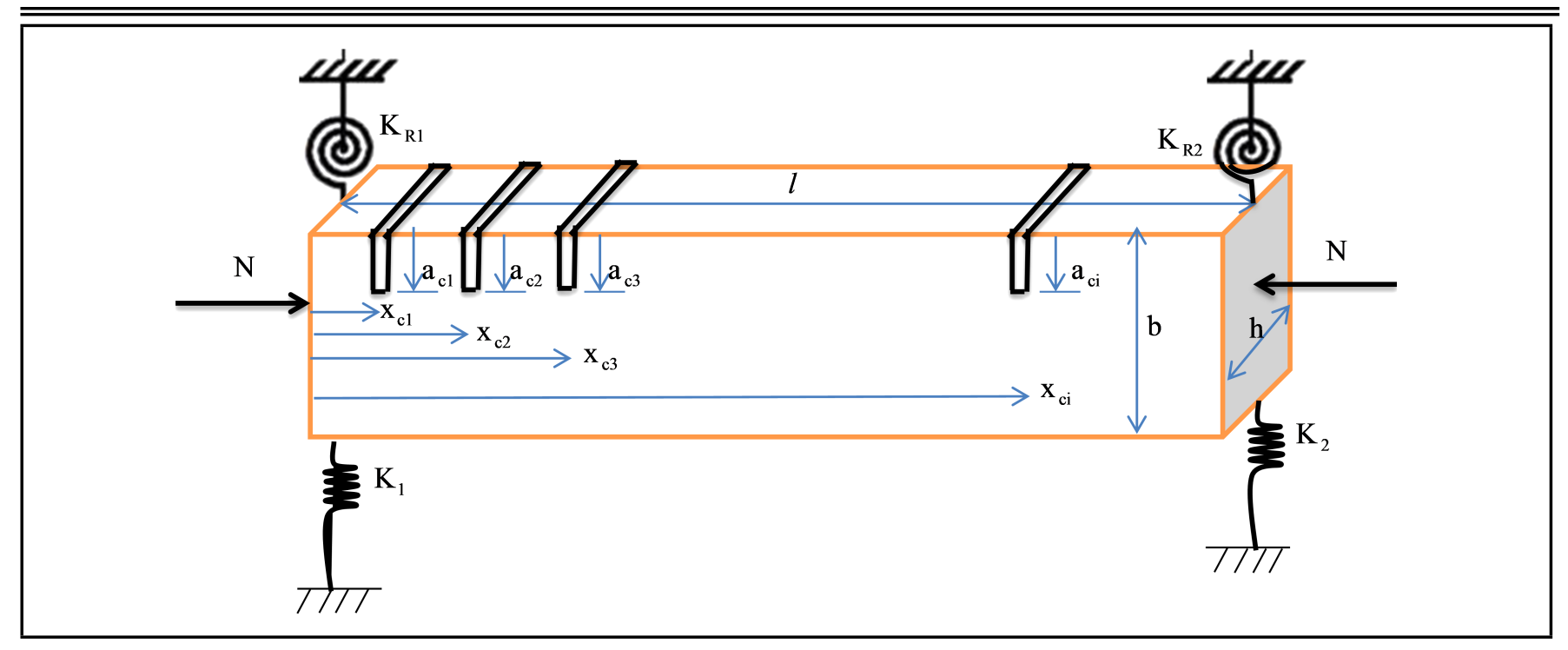

Figure 1. A multi-cracked axially loaded beam with $i$-edge open cracks carrying linear and rotational springs at both ends.

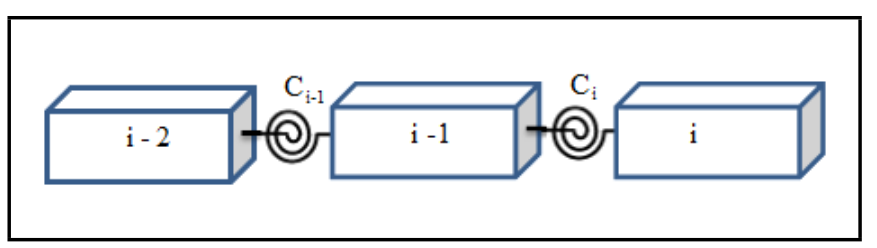

Figure 2. Beam elements jointed by a massless rotational spring.

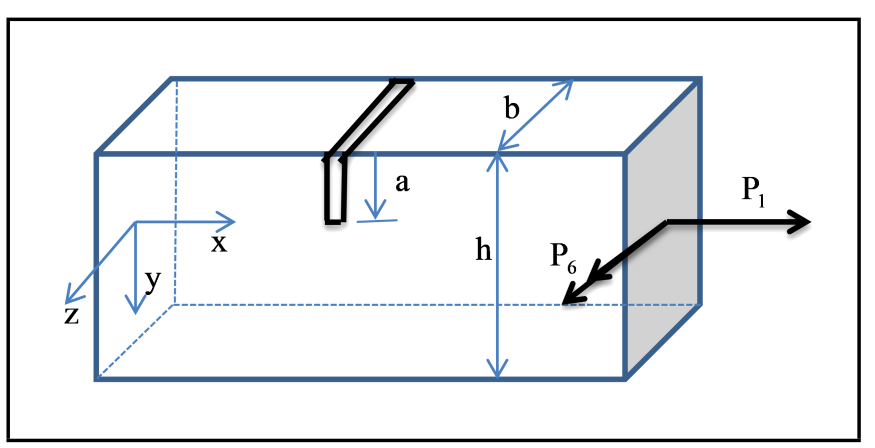

Figure 3. Beam with an open edge crack under axial loading and bending moment.

In this study, the stress intensity factors are:

$$
\begin{array}{ll}
K_{\mathrm{I} 1}=\sigma_{1} \sqrt{\pi a} F_{11}(a / h), & \sigma_{1}=\frac{P_{1}}{b h} ; \\
K_{\mathrm{I} 6}=\sigma_{6} \sqrt{\pi a} F_{16}(a / h), & \sigma_{6}=\frac{6 P_{6}}{b h^{2}} ;
\end{array}
$$

where

$F_{11}(a / h)=\sqrt{\frac{2 h}{\pi a} \tan \left(\frac{\pi a}{2 h}\right)} \frac{0.752+2.02\left(\frac{a}{h}\right)+0.37\left(1-\sin \left(\frac{\pi a}{2 h}\right)\right)^{3}}{\cos \left(\frac{\pi a}{2 h}\right)}$, and $F_{16}(a / h)=\sqrt{\frac{2 h}{\pi a} \tan \left(\frac{\pi a}{2 h}\right)} \frac{0.923+0.199\left(1-\sin \left(\frac{\pi a}{2 h}\right)\right)^{4}}{\cos \left(\frac{\pi a}{2 h}\right)}$.

Now, the flexibility coefficient can be calculated as a combination of axial loadings and bending moments as:

$$
C_{i j}=\frac{\partial^{2}}{\partial P_{i} \partial P_{j}} \int_{A_{c}}\left(\frac{1-\nu^{2}}{E}\right)\left(K_{\mathrm{I} 1}+K_{\mathrm{I} 6}\right)^{2} d A .
$$

In this study, the flexural vibration of the beam is the only significant load in Eq. (5a), therefore, the contribution of axial load component to the strain energy of the system is very small.
Therefore, the only component in the flexibility matrix is $C_{66}$, which can be calculated as:

$$
C_{66}=\left(1-\nu^{2}\right) \frac{72 \pi}{E b h^{2}}\left(\int_{0}^{\varphi} \varphi F_{16}^{2}(\phi) d \phi\right) ;
$$

where $\phi=a / h$.

The solution of Eq. (1) can be written as:

$$
y(x, t)=Y(x) e^{i \omega t} ;
$$

where $Y(x), \omega, i$, and $x$ are the modal shape, the circular frequency, the imaginary number, and the spatial position on the $x$-axis, respectively.

Substituting Eq. (6) into Eq. (1) leads to:

$$
\frac{d^{4} Y(x)}{d x^{4}} \pm \frac{N}{E I} \frac{d^{2} Y(x)}{d x^{2}}-\frac{\rho A \omega^{2}}{E I} Y(x)=0 .
$$

The general form solution of Eq. (7) is:

$$
\begin{aligned}
Y(x)= & A_{1} \cos (\alpha x)+A_{2} \sin (\alpha x)+ \\
& A_{3} \cosh (\beta x)+A_{4} \sinh (\beta x) ;
\end{aligned}
$$

where $\alpha=\sqrt{\left(\frac{N}{2 E I}\right)^{2}+\sqrt{\left(\frac{N}{2 E I}\right)^{2}+\left(\frac{\rho A}{E I}\right) \omega^{2}}}$,

$\beta=\sqrt{-\left(\frac{N}{2 E I}\right)^{2}+\sqrt{\left(\frac{N}{2 E I}\right)^{2}+\left(\frac{\rho A}{E I}\right) \omega^{2}}}$ and $A_{1}$ to $A_{4}$ are unknown constants.

The slope $\theta(x)$, bending moment $M(x)$, and shear force $V(x)$ can be obtained as:

$$
\begin{gathered}
\theta(x)=\frac{\partial Y(x)}{\partial x}=\alpha\left[-A_{1} \sin (\alpha x)+A_{2} \cos (\alpha x)\right]+ \\
\beta\left[A_{3} \sinh (\beta x)+A_{4} \cosh (\beta x)\right] ;
\end{gathered}
$$

$$
M(x)=E I \frac{\partial^{2} Y(x)}{\partial x^{2}}=E I \alpha^{2}\left[-A_{1} \cos (\alpha x)-A_{2} \sin (\alpha x)\right]+
$$$$
E I \beta^{2}\left[A_{3} \cosh (\beta x)+A_{4} \sinh (\beta x)\right] ;
$$

$V(x)=E I \frac{\partial^{3} Y(x)}{\partial x^{3}} \pm N \frac{\partial Y(x)}{\partial x}=$

$\left(E I \alpha^{3}-N \alpha\right)\left[A_{1} \sin (\alpha x)-A_{2} \cos (\alpha x)\right]+$

$\left(E I \beta^{3}+N \beta\right)\left[A_{3} \sinh (\beta x)+A_{4} \cosh (\beta x)\right]$. 


$$
[S(x)]=\left[\begin{array}{cccc}
\cos (\alpha x) & \sin (\alpha x) & \cosh (\beta x) & \sinh (\beta x) \\
-\alpha \sin (\alpha x) & \alpha \cos (\alpha x) & \beta \sinh (\beta x) & \beta \cosh (\beta x) \\
-E I \alpha^{2} \cos (\alpha x) & -E I \alpha^{2} \sin (\alpha x) & E I \beta^{2} \cosh (\beta x) & E I \beta^{2} \sinh (\beta x) \\
\left(E I \alpha^{3}-N \alpha\right) \sin (\alpha x) & -\left(E I \alpha^{3}-N \alpha\right) \cos (\alpha x) & \left(E I \beta^{3}+N \beta\right) \sinh (\beta x) & \left(E I \beta^{3}+N \beta\right) \cosh (\beta x)
\end{array}\right] .
$$

At the location of the open edge crack, the two beam segments $i, i+1$ are connected by a massless, rotational spring, as shown in Fig. 3. Equation (6) and Eqs. (8a) to (8d) can be written in a matrix form for both segments, $i$ and $i+1$, respectively, as:

$$
\begin{gathered}
\left\{\begin{array}{c}
Y_{i}(x) \\
\theta_{i}(x) \\
M_{i}(x) \\
V_{i}(x)
\end{array}\right\}=[S(x)]\left\{\begin{array}{l}
A_{1, i} \\
A_{2, i} \\
A_{3, i} \\
A_{4, i}
\end{array}\right\} ; \\
\left\{\begin{array}{c}
Y_{i+1}(x) \\
\theta_{i+1}(x) \\
M_{i+1}(x) \\
V_{i+1}(x)
\end{array}\right\}=[S(x)]\left\{\begin{array}{l}
A_{1, i+1} \\
A_{2, i+1} \\
A_{3, i+1} \\
A_{4, i+1}
\end{array}\right\} ;
\end{gathered}
$$

where $[S(x)]$ is given by Eq. (9c).

The compatibility requirements at the crack position, $x_{c}$, which are the continuity of the deflection, bending moment, shear force, and the discontinuity of slopes for segments $i$ and $i+1$, can be written in matrix form as:

$$
\left\{\begin{array}{c}
Y_{i+1}\left(x_{c}\right) \\
\theta_{i+1}\left(x_{c}\right) \\
M_{i+1}\left(x_{c}\right) \\
V_{i+1}\left(x_{c}\right)
\end{array}\right\}=\left[\begin{array}{cccc}
1 & 0 & 0 & 0 \\
0 & 1 & C_{i} & 0 \\
0 & 0 & 1 & 0 \\
0 & 0 & 0 & 1
\end{array}\right]\left\{\begin{array}{c}
Y_{i}\left(x_{c}\right) \\
\theta_{i}\left(x_{c}\right) \\
M_{i}\left(x_{c}\right) \\
V_{i}\left(x_{c}\right)
\end{array}\right\}
$$

Equation (10) can be written as:

$$
\left\{Q_{i+1}\left(x_{i}\right)\right\}=\left[C_{i}\right]\left\{Q_{i}\left(x_{i}\right)\right\} .
$$

Equation (9a) can be rewritten for a segment, $x_{i-1}<x<x_{i}$, as:

$$
\left\{Q_{i}(x)\right\}=[S(x)]\left\{A_{i}\right\}
$$

where $\left\{Q_{i}(x)\right\}=\left\{\begin{array}{c}Y_{i+1}\left(x_{c}\right) \\ \theta_{i+1}\left(x_{c}\right) \\ M_{i+1}\left(x_{c}\right) \\ V_{i+1}\left(x_{c}\right)\end{array}\right\}$, and $\left\{A_{i}\right\}=\left\{\begin{array}{c}A_{1, i} \\ A_{2, i} \\ A_{3, i} \\ A_{4, i}\end{array}\right\}$.

The boundary conditions of the beam using equilibrium equations can be expressed as:

$$
\begin{aligned}
M(0) & =K_{R 1} \theta(0) ; \\
V(0) & =-K_{1} Y(0) ; \\
M(l) & =-K_{R 2} \theta(l) ; \\
V(l) & =K_{2} Y(l) .
\end{aligned}
$$

In order to calculate the natural frequencies and corresponding mode shapes, the characteristic equation can be derived as:

1. At $x=0$, and at $0<x<x_{1}$ Eq. (12) can be rewritten, respectively, as:

$$
\begin{aligned}
& \left\{Q_{1}(0)\right\}=[S(0)]\left\{A_{i}\right\} ; \\
& \left\{Q_{1}(x)\right\}=[S(x)]\left\{A_{i}\right\} .
\end{aligned}
$$

Substituting Eq. (14a) into Eq. (14b) leads to:

$$
\left\{Q_{1}(x)\right\}=[S(x)]\left\{Q_{1}(0)\right\}[S(0)]^{-1} .
$$

2. At $x=x_{1}$, using Eq. (11) and Eq. (15) becomes:

$$
\left\{Q_{2}\left(x_{1}\right)\right\}=\left[C_{1}\right]\left[S\left(x_{1}\right)\right]\left\{Q_{1}(0)\right\}[S(0)]^{-1} .
$$

3. At segment $x_{1}<x<x_{2}$, a similar equation can be written as:

$$
\left\{Q_{2}(x)\right\}=[S(x)]\left[S\left(x_{1}\right)\right]^{-1}\left\{Q_{1}(0)\right\} .
$$

Substituting Eq. (16) into Eq. (17a) leads to:

$$
\left\{Q_{2}(x)\right\}=[S(x)]\left[S\left(x_{1}\right)\right]^{-1}\left[C_{1}\right]\left[S\left(x_{1}\right)\right]\left\{Q_{1}(0)\right\}[S(0)]^{-1} .
$$

Introduce two matrixes, $\left[T_{i}\right]$ and $\left[T c_{i}\right]$, where

$$
\begin{aligned}
{\left[T_{i}\right] } & =\left[S\left(x_{i}\right)\right]\left[S\left(x_{i-1}\right)\right]^{-1} ; \\
{\left[T c_{i}\right] } & =\left[C_{i}\right]\left[S\left(x_{i}\right)\right]\left[S\left(x_{i-1}\right)\right]^{-1} .
\end{aligned}
$$

Using Eqs. (17b) and (18b) leads to:

$$
\left\{Q_{2}(x)\right\}=[S(x)]\left[S\left(x_{1}\right)\right]^{-1}\left[T c_{1}\right]\left\{Q_{1}(0)\right\} .
$$

4. At segment $x_{i}<x<l$, a similar equation can be written, which is:

$$
\begin{aligned}
\left\{Q_{i+1}(x)\right\}= & {[S(x)]\left[S\left(x_{1}\right)\right]^{-1}\left[T c_{i}\right]\left[T c_{i-1}\right]\left[T c_{i-2}\right] \ldots } \\
& \ldots\left[T c_{2}\right]\left[T c_{1}\right]\left\{Q_{1}(0)\right\} .
\end{aligned}
$$

5. At the end of the beam, Eq. (20) can be written as:

$$
\begin{aligned}
\left\{Q_{i+1}(l)\right\}= & {\left[T_{i+1}\right]\left[T c_{i}\right]\left[T c_{i-1}\right]\left[T c_{i-2}\right] \ldots } \\
& \ldots\left[T c_{2}\right]\left[T c_{1}\right]\left\{Q_{1}(0)\right\} .
\end{aligned}
$$

Let

$$
[T]_{i}=\left[T_{i+1}\right]\left[T c_{i}\right]\left[T c_{i-1}\right]\left[T c_{i-2}\right] \ldots\left[T c_{2}\right]\left[T c_{1}\right] .
$$

Then, Eq. (21) can be rewritten as:

$$
\left\{Q_{i+1}(l)\right\}=[T]_{i}\left\{Q_{1}(0)\right\}
$$

where $[T]_{i}=\left[\begin{array}{llll}T_{11} & T_{12} & T_{13} & T_{14} \\ T_{21} & T_{22} & T_{23} & T_{24} \\ T_{31} & T_{32} & T_{33} & T_{34} \\ T_{41} & T_{42} & T_{43} & T_{44}\end{array}\right]$

6. The continuity conditions of the deflection, slope, moment, and shear at $x=0$ and $x=l$ leads to:

$$
\left\{\begin{array}{c}
Y_{i+1}(l) \\
\theta_{i+1}(l) \\
-K_{R 2} \theta_{i+1}(l) \\
K_{2} Y_{i+1}(l)
\end{array}\right\}=[T]\left\{\begin{array}{c}
Y_{1}(0) \\
\theta_{1}(0) \\
K_{R 1} \theta_{1}(0) \\
-K_{1} Y_{1}(0)
\end{array}\right\}
$$




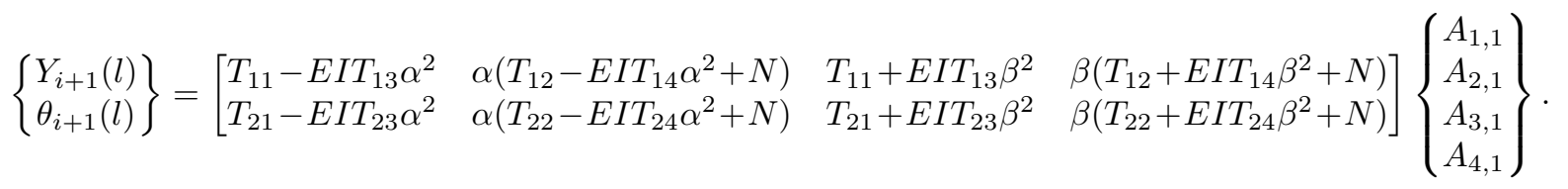

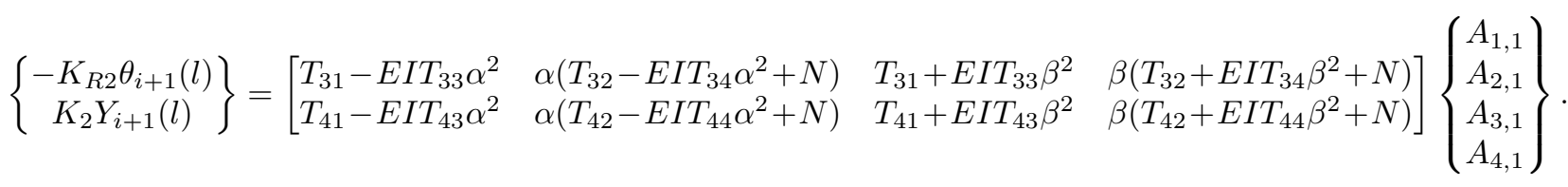

7. Equation (24) can be rewritten as:

$$
\begin{aligned}
& \left\{\begin{array}{c}
Y_{i+1}(l) \\
\theta_{i+1}(l)
\end{array}\right\}=\left[\begin{array}{ll}
T_{11}-K_{1} T_{14} & T_{12}+K_{R 1} T_{13} \\
T_{21}-K_{1} T_{24} & T_{22}+K_{R 1} T_{23}
\end{array}\right]\left\{\begin{array}{c}
Y_{1}(0) \\
\theta_{1}(0)
\end{array}\right\} ; \\
& \left\{\begin{array}{c}
-K_{R 2} \theta_{i+1}(l) \\
K_{2} Y_{i+1}(l)
\end{array}\right\}=\left[\begin{array}{ll}
T_{31}-K_{1} T_{34} & T_{32}+K_{R 1} T_{33} \\
T_{41}-K_{1} T_{44} & T_{42}+K_{R 1} T_{43}
\end{array}\right]\left\{\begin{array}{c}
Y_{1}(0) \\
\theta_{1}(0)
\end{array}\right\} .
\end{aligned}
$$

8. The characteristic equation can be obtained by substitution of Eq. (25a) into Eq. (25b)

$$
F_{1} F_{4}-F_{2} F_{3}=0
$$

where

$$
\begin{aligned}
& F_{1}=-K_{R 2} T_{21}+K_{1} K_{R 2} T_{24}-T_{31}+K_{1} T_{34} ; \\
& F_{2}=-K_{R 2} T_{22}-K_{R 1} K_{R 2} T_{23}-T_{32}-K_{R 1} T_{33} ; \\
& F_{3}=K_{2} T_{11}-K_{1} K_{2} T_{14}-T_{41}+K_{1} T_{44} ; \\
& F_{4}=K_{2} T_{12}+K_{2} K_{R 1} T_{13}-T_{42}-K_{R 1} T_{43} .
\end{aligned}
$$

Characteristic Eq. (26) can be derived for different boundary conditions as:

a) For fixed-free boundaries $\left(K_{1}=K_{R 1}=\infty\right)$, $T_{34} T_{43}-T_{33} T_{44}=0$.

b) For pinned-pinned boundaries $\left(K_{1}=K_{2}=\infty\right)$, $T_{34} T_{12}-T_{32} T_{14}=0$.

c) For fixed-pinned boundaries $\left(K_{1}=K_{2}=K_{R 1}=\infty\right)$, $T_{34} T_{13}-T_{33} T_{14}=0$.

d) For fixed-fixed boundaries $\left(K_{1}=K_{2}=K_{R 1}=K_{R 2}=\infty\right)$, $T_{24} T_{13}-T_{23} T_{14}=0$.

e) For free-free boundaries, $T_{31} T_{42}-T_{32} T_{41}=0$.

The corresponding mode shapes can be obtained as:

1. At $x=0$, Eq. (12) can be written as:

$$
\begin{gathered}
\left\{\begin{array}{c}
Y_{1}(0) \\
\theta_{1}(0) \\
K_{R 1} \theta_{1}(0) \\
-K_{1} Y_{1}(0)
\end{array}\right\}= \\
{\left[\begin{array}{cccc}
1 & 0 & 1 & 0 \\
0 & \alpha & 0 & \beta \\
-E I \alpha^{2} & 0 & E I \beta^{2} & 0 \\
0 & -E I \alpha^{3}+N \alpha & 0 & E I \beta^{3}+N \beta
\end{array}\right]\left\{\begin{array}{l}
A_{1,1} \\
A_{2,1} \\
A_{3,1} \\
A_{4,1}
\end{array}\right\} .}
\end{gathered}
$$

Equation (27) can be rewritten as:

$$
\left\{\begin{array}{l}
Y_{1}(0) \\
\theta_{1}(0)
\end{array}\right\}=\left[\begin{array}{llll}
1 & 0 & 1 & 0 \\
0 & \alpha & 0 & \beta
\end{array}\right]\left\{\begin{array}{l}
A_{1,1} \\
A_{2,1} \\
A_{3,1} \\
A_{4,1}
\end{array}\right\}
$$

$\left\{\begin{array}{l}K_{R 1} \theta_{1}(0) \\ -K_{1} Y_{1}(0)\end{array}\right\}=$

$$
\left[\begin{array}{cccc}
-E I \alpha^{2} & 0 & E I \beta^{2} & 0 \\
0 & -E I \alpha^{3}+N \alpha & 0 & E I \beta^{3}+N \beta
\end{array}\right]\left\{\begin{array}{l}
A_{1,1} \\
A_{2,1} \\
A_{3,1} \\
A_{4,1}
\end{array}\right\}
$$

Substituting Eq. (28a) into Eq. (28b) yields:

$$
\left[\begin{array}{llll}
Q_{11} & Q_{12} & Q_{13} & Q_{14} \\
Q_{21} & Q_{22} & Q_{23} & Q_{24}
\end{array}\right]\left\{\begin{array}{c}
A_{1,1} \\
A_{2,1} \\
A_{3,1} \\
A_{4,1}=0
\end{array}\right\}
$$

where $Q_{11}=E I \alpha^{2}, Q_{12}=K_{R 1} \alpha, Q_{13}=-E I \beta^{2}, Q_{14}=$ $K_{R 1} \beta, Q_{21}=-K_{1}, Q_{22}=E I \alpha^{3}-N \alpha, Q_{23}=-K_{1}$, $Q_{24}=-E I \beta^{3}-N \beta$.

2. At $x=l$, substituting Eqs. (9c), (13c), (13d), and (14a) into Eq. (24) yields Eqs. (30a) and (30b).

Substituting Eq. (30a) into Eq. (30b) leads to:

$$
\left[\begin{array}{llll}
Q_{31} & Q_{32} & Q_{33} & Q_{34} \\
Q_{41} & Q_{42} & Q_{43} & Q_{44}
\end{array}\right]\left\{\begin{array}{l}
A_{1,1} \\
A_{2,1} \\
A_{3,1} \\
A_{4,1}
\end{array}\right\}=0
$$

where

$$
\begin{aligned}
Q_{31}= & -K_{R 2}\left(T_{21}-E I T_{23} \alpha^{2}\right)-T_{31}+E I T_{33} \alpha^{2} ; \\
Q_{32}= & -K_{R 2} \alpha\left(T_{22}-E I T_{24} \alpha^{2}+N T_{34}\right)- \\
& \alpha\left(T_{32}-E I T_{34} \alpha^{2}+N T_{34}\right) ; \\
Q_{33}=- & K_{R 2}\left(T_{21}+E I T_{23} \beta^{2}\right)-T_{31}-E I T_{33} \beta^{2} ; \\
Q_{34}=- & K_{R 2} \beta\left(T_{22}+E I T_{24} \beta^{2}+N T_{24}\right)- \\
& \beta\left(T_{32}+E I T_{34} \beta^{2}+N T_{34}\right) ; \\
Q_{41}= & K_{2}\left(T_{11}-E I T_{13} \alpha^{2}\right)-T_{41}+E I T_{43} \alpha^{2} ; \\
Q_{42}= & K_{2} \alpha\left(T_{12}-E I T_{14} \alpha^{2}+N T_{14}\right)- \\
& \alpha\left(T_{42}-E I T_{44} \alpha^{2}+N T_{44}\right) ;
\end{aligned}
$$




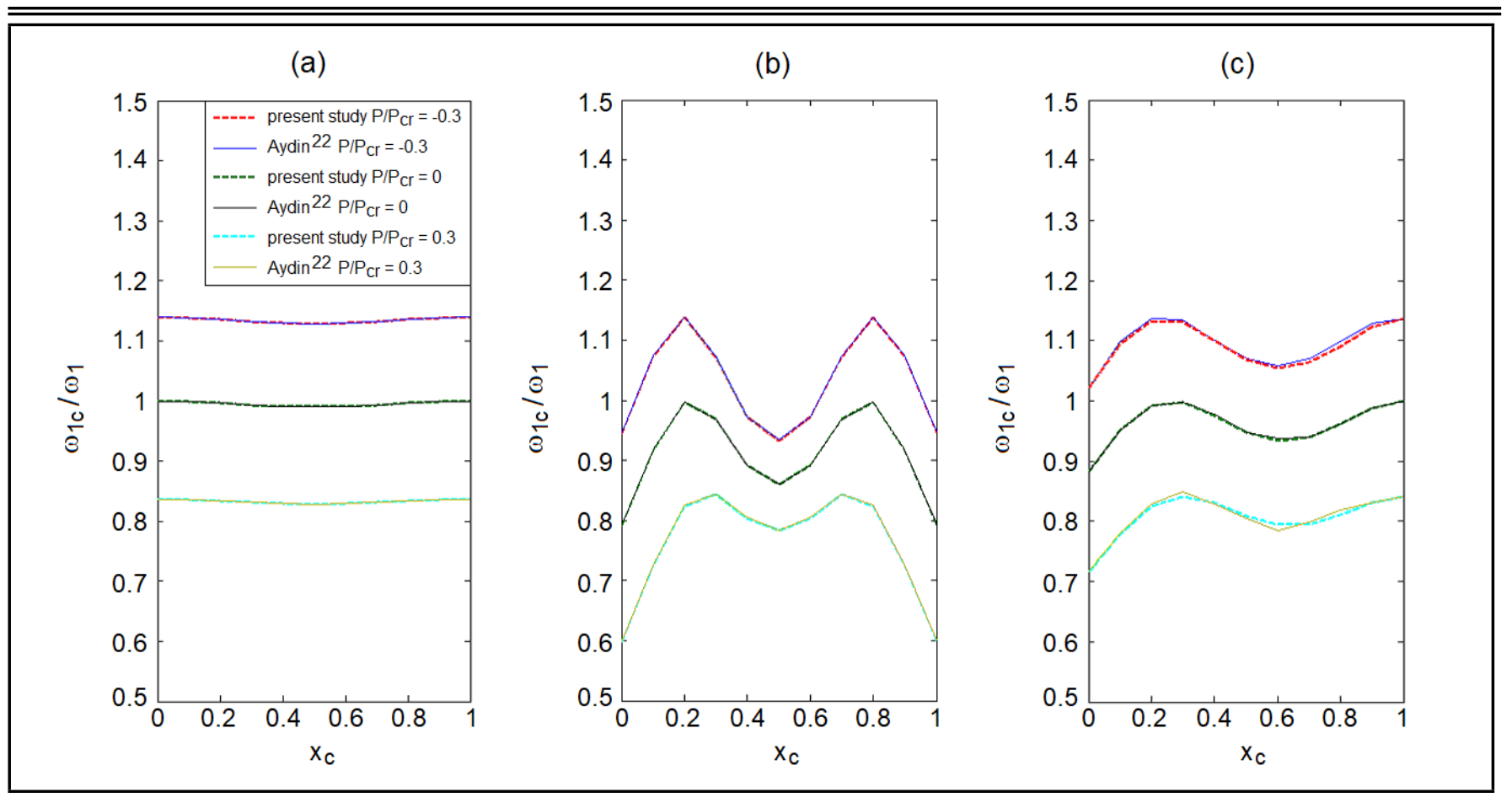

Figure 4. The first three non-dimensional natural frequencies of (a) hinged-hinged beam with single crack with $a / h=0.1$, (b) fixed-fixed beam with single crack with $a / h=0.3$, and (c) fixed-hinged beam with single crack with $a / h=0.5$. The curves are obtained for $P / P_{c r}$ values of -0.3 , 0 , and 0.3 (from top to bottom).

$$
\begin{aligned}
Q_{43}= & K_{2}\left(T_{11}+E I T_{13} \beta^{2}\right)-T_{41}-E I T_{43} \beta^{2} ; \\
Q_{44}= & K_{2} \beta\left(T_{12}+E I T_{14} \beta^{2}+N T_{14}\right)- \\
& \beta\left(T_{42}+E I T_{44} \beta^{2}+N T_{44}\right) .
\end{aligned}
$$

Combining Eq. (29) and Eq. (31) yields:

$$
\left[\begin{array}{llll}
Q_{11} & Q_{12} & Q_{13} & Q_{14} \\
Q_{21} & Q_{22} & Q_{23} & Q_{24} \\
Q_{31} & Q_{32} & Q_{33} & Q_{34} \\
Q_{41} & Q_{42} & Q_{43} & Q_{44}
\end{array}\right]\left\{\begin{array}{l}
A_{1,1} \\
A_{2,1} \\
A_{3,1} \\
A_{4,1}
\end{array}\right\}=0
$$

The unknown coefficients of Eq. (32) correspond to the mode shapes of the first crack position, i.e., at $x=x c_{1}$. For other crack locations, the unknown coefficients can be obtained using the coefficients of the previous crack as:

$$
\left\{A_{i}\right\}=\left[S\left(x_{i-1}\right)\right]^{-1}\left[C_{i-1}\right]\left[S\left(x_{i-1}\right)\right]\left\{A_{i-1}\right\} .
$$

\section{RESULTS AND DISCUSSION}

\subsection{Validation of Results}

In order to examine the present results with those available in literature, three different boundary conditions are used, namely, hinged-hinged, fixed-hinged, and fixed-fixed. Also, three different values of $P / P_{c r}$ are used, which are $0.3,0$, -0.3 . These values are chosen to reflect the axial loading conditions in real life structures, where $P_{c r}$ is the critical buckling load of the intact beam $\left(P_{c r}=\pi^{2} E I / l^{2}\right)$. The geometric and material properties of the intact beam used are $l=1 \mathrm{~m}$, $b=0.1 \mathrm{~m}, h=0.1 \mathrm{~m}, \rho=7850 \mathrm{~kg} / \mathrm{m}^{3}, E=200 \mathrm{GPa}$, and $\nu=0.3$. Figures 4(a), 4(b), and 4(c) show the first non-dimensional natural frequency ratio, $\omega_{c r} / \omega_{i n}$, obtained in this study with those obtained by Aydin versus the nondimensional crack location, $x / l$, for a beam with $a / h=0.1$, hinged-hinged, $a / h=0.3$, fixed-hinged, and $a / h=0.5$, fixed-fixed, respectively. ${ }^{22}$ It is clear from the figures that the results obtained in this study agree well with those obtained by Aydin. ${ }^{22}$

\subsection{Effects of One Crack and Axial Load on Natural Frequencies}

The geometric and material properties of the intact beam are the same as those in the validation section. Figures 5, 6,7 , and 8 show the first three non-dimensional natural frequencies of a beam with a single crack versus the crack location, for hinged-hinged, fixed-fixed, fixed-hinged, and fixedfree boundaries, respectively. In all figures, figure (a) represents $P / P_{c r}=0$, figure (b) represents $P / P_{c r}=-0.3$, and figure (c) represents $P / P_{c r}=0.3$. Eight values of the aspect ratio $a / h$ are used in all figures, $0,0.1,0.2,0.3,0.4,0.5$, 0.6 , and 0.7 . It is obvious from all figures that an increase in the aspect ratio leads to a decrease in the natural frequencies. The first non-dimensional frequencies are most affected by the severity of the cracks and the magnitude of the axial force. It is clear from the figures that the natural frequencies obtained do not change with different values of aspect ratio $(a / h)$ at the location of the zero-crossing of the mode shape. As an example, it is located at $0.5 l$, for hinged-hinged boundaries for the second non-dimensional natural frequency. Also, the natural frequencies obtained do not change with different values of aspect ratio $(a / h)$ at certain locations in the beam. Those locations can be called critical points for a given frequency and are different with differing boundary conditions, as an example for the first non-dimensional frequencies, located at $0.21 l$ and $0.79 l$ for fixed-fixed boundaries, and at $0.25 l$ for fixed-hinged boundaries. An interesting observation overlooked by researchers is that for fixed-fixed and fixed-hinged boundary conditions, the locations of critical points for the first 


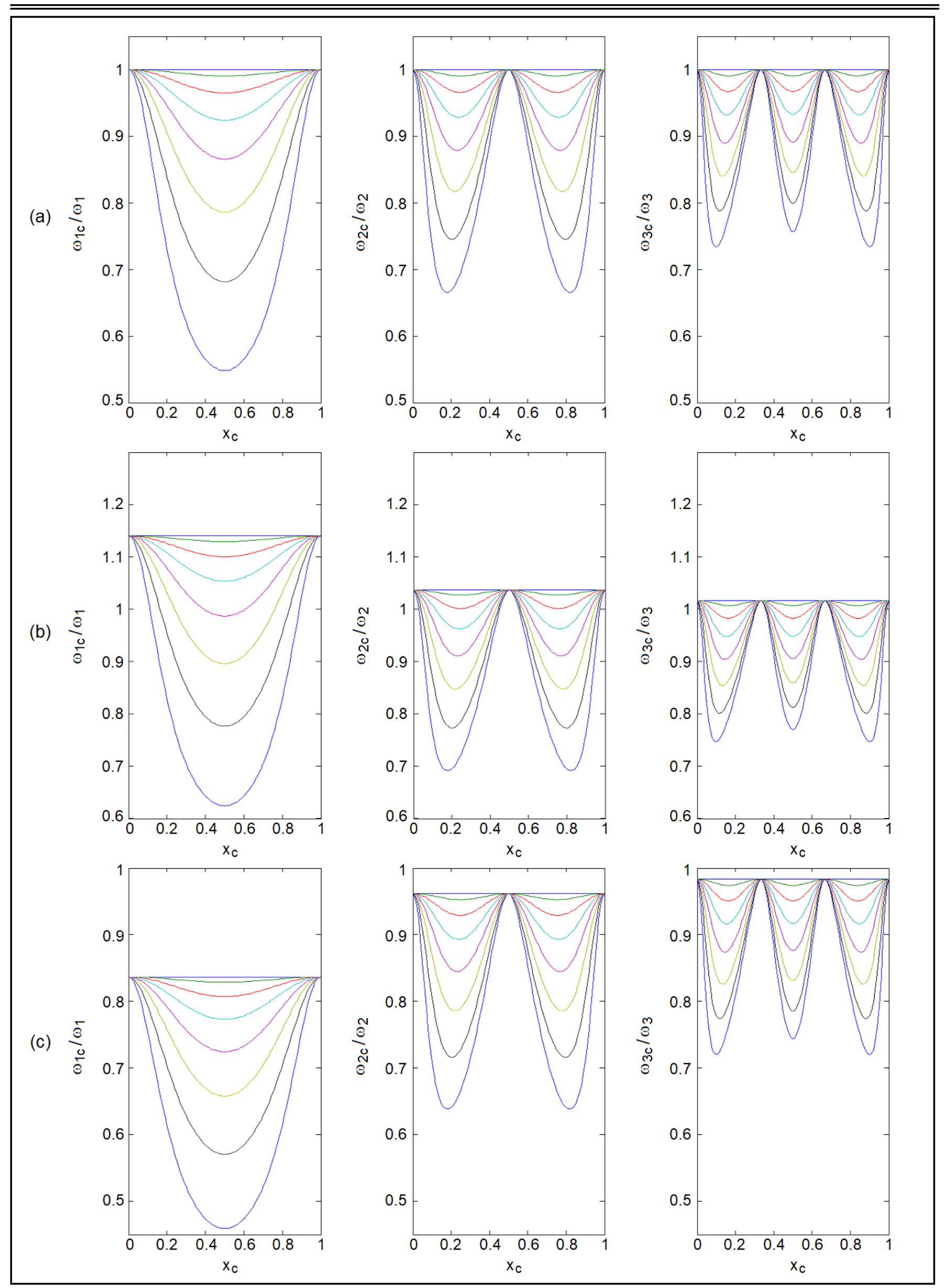

Figure 5. The first three non-dimensional natural frequencies of a hinged-hinged beam with a single crack for (a) $P / P_{c r}=0,(\mathrm{~b}) P / P_{c r}=-0.3$, and (c) $P / P_{c r}=0.3$. The curves are obtained for $a / h$ values of $0,0.1,0.2,0.3,0.4,0.5,0.6$, and 0.7 (from top to bottom). 


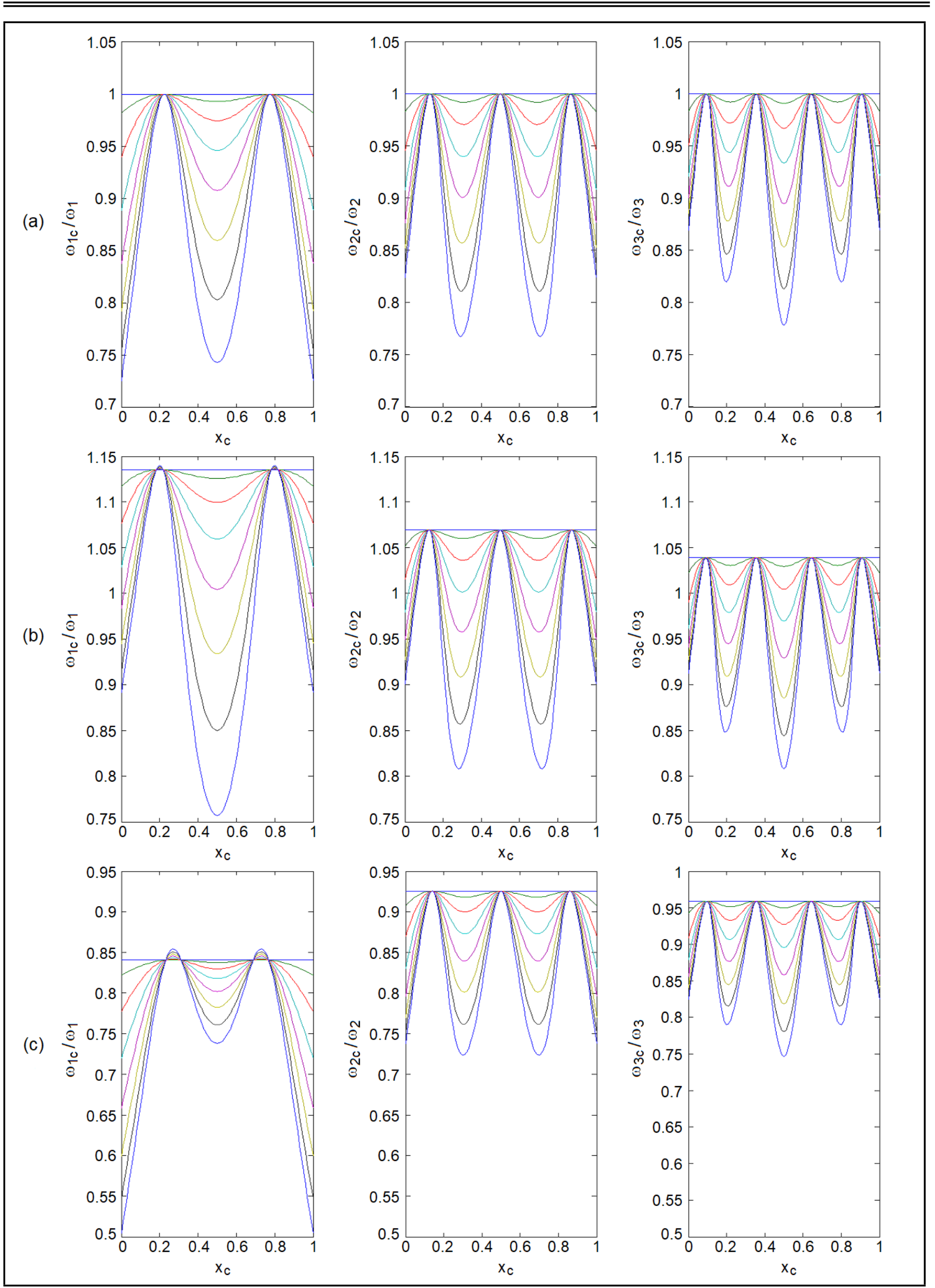

Figure 6. Same as Fig. 5, but with a fixed-fixed beam. 


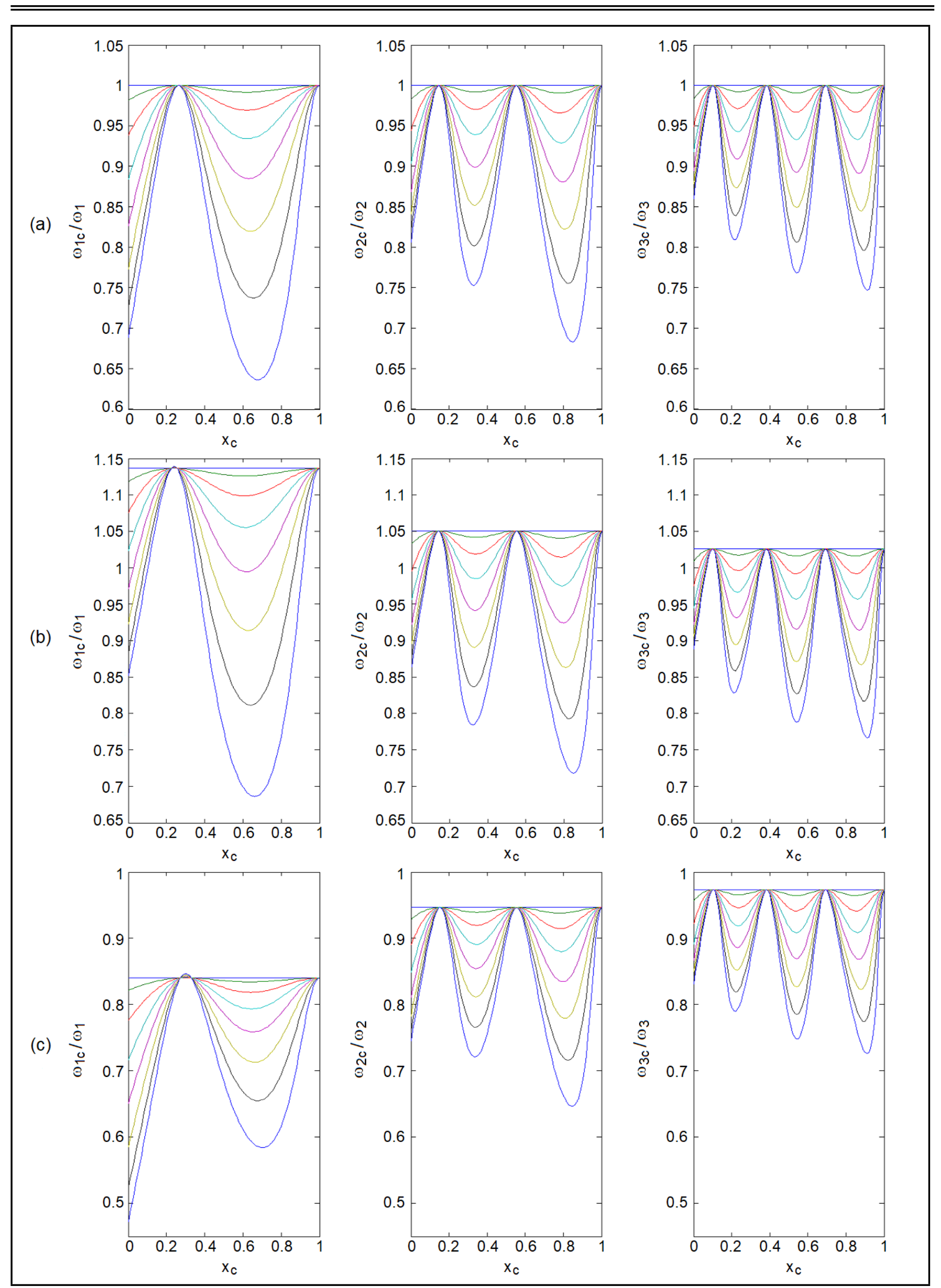

Figure 7. Same as Fig. 5, but with a fixed-hinged beam. 


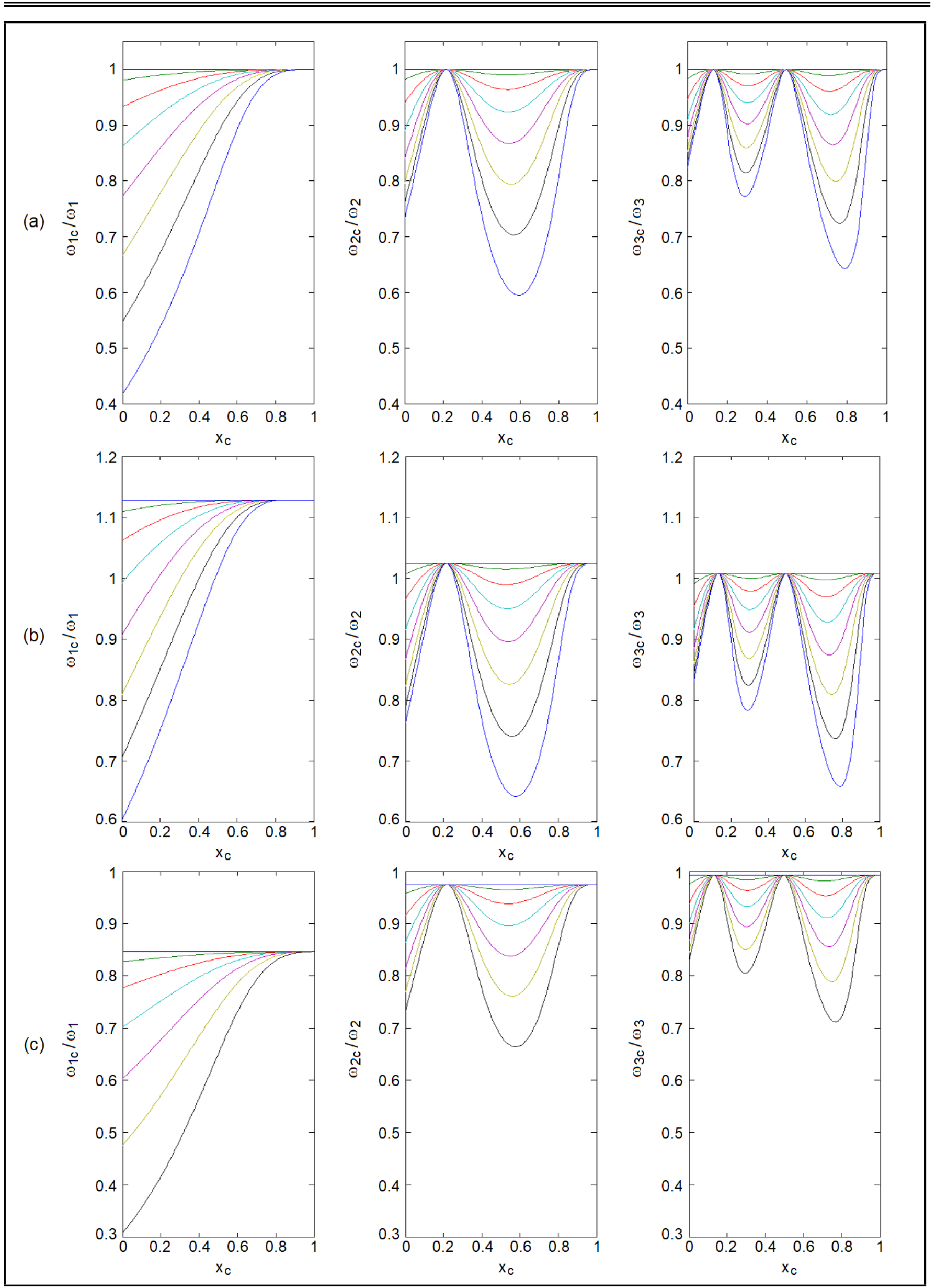

Figure 8. Same as Fig. 5, but with a fixed-free beam beam and values of $a / h: 0,0.1,0.2,0.3,0.4,0.5$, and 0.6 for (c). 
non-dimensional frequencies are shifted toward the fixed supports when the beam is axially loaded in tension and toward the centre of the beam when the beam is axially loaded in compression. Those locations are at $0.19 l, 0.21 l, 0.79 l$, and $0.81 l$, and at $0.23 l, 0.26 l, 0.74 l$, and $0.79 l$ for tension and compression loaded beams, respectively, for fixed-fixed boundaries, and at $0.21 l$, and $0.23 l$, and $0.25 l$, and $0.27 l$ for tension and compression loaded beams, respectively, for fixed-hinged boundaries. Another interesting observation also overlooked by researchers is that for axially loaded fixed-fixed and fixed-hinged beams, the first cracked natural frequencies obtained are higher than those of the intact beam near the critical points, suggesting that in the damage detection process, one should be careful when measuring the natural frequencies near these locations. It is clear from the results that identical natural frequencies are always obtained for different crack locations, except for the first non-dimensional natural frequencies having fixed-free boundaries. For an axially loaded beam, it is clear from the figures that the non-dimensional natural frequencies for all modes of the beam under tensile force are greater than those of the same beam under a compressive force, because the tensile force stiffens the beam while the compressive force softens the beam for all boundary conditions. For an axially loaded hinged-hinged beam, the first non-dimensional natural frequency is most affected when the cracks are located near the supports. A maximum increase of $14 \%$ and a $17 \%$ decrease are obtained for $P / P_{c r}=0.3$ and $P / P_{c r}=-0.3$, respectively, for all values of aspect ratios. At the mid-span of the beam, an $11 \%$ increase and a $12 \%$ decrease are obtained for $P / P_{c r}=0.3$ and $P / P_{c r}=-0.3$, respectively, for an aspect ratio of 0.5 . For an axially loaded fixed-fixed beam, the first non-dimensional natural frequency is also the most affected when the cracks are located near the supports. A maximum $14 \%$ increase and $16 \%$ decrease are obtained for $P / P_{c r}=0.3$ and $P / P_{c r}=-0.3$, respectively, for aspect ratio equal to 0.1 . A maximum $17 \%$ increase and $21 \%$ decrease are obtained for $P / P_{c r}=0.3$ and $P / P_{c r}=-0.3$, respectively, for aspect ratio equal to 0.7 . At the mid-span of the beam, a $13 \%$ increase and $14 \%$ decrease are obtained for $P / P_{c r}=0.3$ and $P / P_{c r}=-0.3$, respectively, for an aspect ratio of 0.2 . These percentages of increase and decrease do decrease as the value of aspect ratio increases. For an axially loaded fixed-hinged beam, the first non-dimensional natural frequency is most affected when the cracks are located near the supports. A maximum $14 \%$ increase and $16 \%$ decrease are obtained for $P / P_{c r}=0.3$ and $P / P_{c r}=-0.3$, respectively, for an aspect ratio of 0.1 . A maximum $16 \%$ increase and $21 \%$ decrease are obtained for $P / P_{c r}=0.3$ and $P / P_{c r}=-0.3$, respectively, for an aspect ratio of 0.7 . At $0.62 l$, a $13 \%$ increase and $14 \%$ decrease are obtained for $P / P_{c r}=0.3$ and $P / P_{c r}=-0.3$, respectively, for an aspect ratio of 0.2 . These percentages of increase and decrease are decreased as the value of aspect ratio increases. It is should be noted here that the location of $0.62 l$ is shifted toward the centre of the beam under tensile loadings and shifted toward the hinged support for the same beam under compressive loadings. For an axially loaded fixed-free beam, the first non-dimensional natural frequency is most affected when the cracks are located near the supports. A maximum $16 \%$ decrease and $13 \%$ increase are obtained for $P / P_{c r}=0.3$ and $P / P_{c r}=-0.3$, respectively, for an aspect ratio of 0.1 . A maximum $12 \%$ decrease and $18 \%$ increase are obtained for $P / P_{c r}=0.3$ and $P / P_{c r}=-0.3$, respectively, for an aspect ratio of 0.7 . It is noted here that a crack location beyond $0.6 \mathrm{l}$ has no significant impact on the first non-dimensional natural frequencies.

\subsection{Effects of Multiple Cracks and Axial Load on Natural Frequencies}

The geometrical and material properties of the intact beam are also used in the validation section. Figures 9, 10, 11, and 12 show the first three non-dimensional natural frequencies of a beam with four cracks versus the crack location, for hinged-hinged, fixed-fixed, fixed-hinged, and fixed-free boundaries, respectively. Again, in all figures, figure (a) represents $P / P_{c r}=0$, figure (b) represents $P / P_{c r}=-0.3$, and figure (c) represents $P / P_{c r}=0.3$. Again, eight values of aspect ratio, $a / h$, are used in all figures, $0,0.1,0.2,0.3,0.4$, $0.5,0.6$, and 0.7 . Three cracks are fixed at locations of maximum variation of non-dimensional frequencies, specifically: at $0.15 l, 0.5 l$, and $0.85 l$; at $0.3 l, 0.5 l$, and $0.7 l$; at $0.3 l, 0.7 l$, and $0.9 l$; and at $0.01 l, 0.6 l$, and $0.8 l$ for hinged-hinged, fixed-fixed, fixed-hinged, and fixed-free boundaries, respectively, while the fourth crack moves along the beam. It is clear from the figures that the presence of four cracks in the beam lowers the nondimensional natural frequencies, with or without axial loading, relative to the case of a single crack. For a hinged-hinged beam, a maximum $27 \%$ and $15 \%$ decrease of the first two nondimensional frequencies occurs for an aspect ratio of 0.5 when the fourth crack is closer to the supports and in the mid-span of the beam, respectively, compare Fig. 5(a) with Fig. 9(a). For a fixed fixed beam, a maximum $16 \%$ and $7 \%$ decrease of the first two non-dimensional frequencies occurs for an aspect ratio of 0.5 when the fourth crack is closer to the supports and in the mid-span of the beam, respectively; compare Fig. 6(a) with Fig. 10(a). For a fixed-hinged beam, a maximum 15\%, 20\%, and $14 \%$ decrease of the first non-dimensional frequencies for an aspect ratio of 0.5 when the fourth crack is closer to the fixed support, closer to the hinged support, and at $0.7 l$, respectively; compare Fig. 7(a) with Fig. 11(a). For a fixed-free beam, a maximum $16 \%$ and $33 \%$ decrease of the first non-dimensional frequencies for an aspect ratio of 0.5 when the fourth crack is closer to the fixed and free supports, respectively; compare Fig. 8(a) with Fig. 12(a).

\subsection{Effects of Number of Cracks on Natural Frequencies and Corresponding Mode Shapes}

Again, the geometrical and material properties of the intact beam are those from the validation section. Figures 13 and 14 show the effects of number of cracks on the first three nondimensional natural frequencies of a beam for hinged-hinged and fixed-free boundaries, respectively. In the two figures, $a / h=0.3$ is used, figure (a) represents $P / P_{c r}=0$, figure (b) represents $P / P_{c r}=-0.3$, and figure (c) represents $P / P_{c r}=0.3$, the solid line represents a beam with one moving crack, the dashed line represents a beam with two cracks; crack at location $0.2 l$ and one moving crack along the beam, and the dotted line represents a beam with three cracks, two cracks located at $0.2 l$ and $0.4 l$, and one moving crack along 


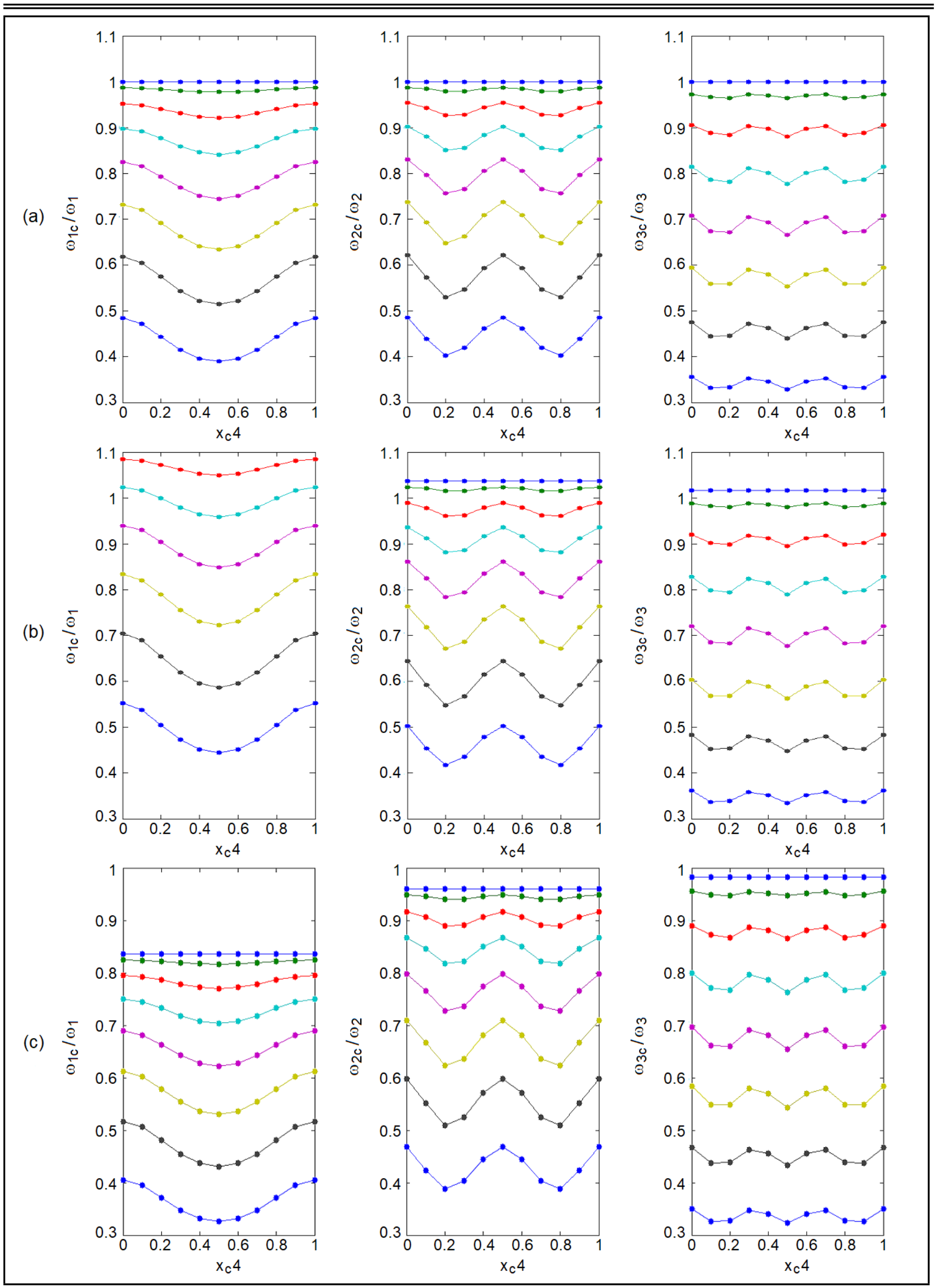

Figure 9. The first three non-dimensional natural frequencies of a hinged-hinged beam with four cracks for (a) $P / P_{c r}=0$, (b) $P / P_{c r}=-0.3$, and (c) $P / P_{c r}=0.3$. The curves are obtained for $a / h$ values of $0,0.1,0.2,0.3,0.4,0.5,0.6$, and 0.7 (from top to bottom). 


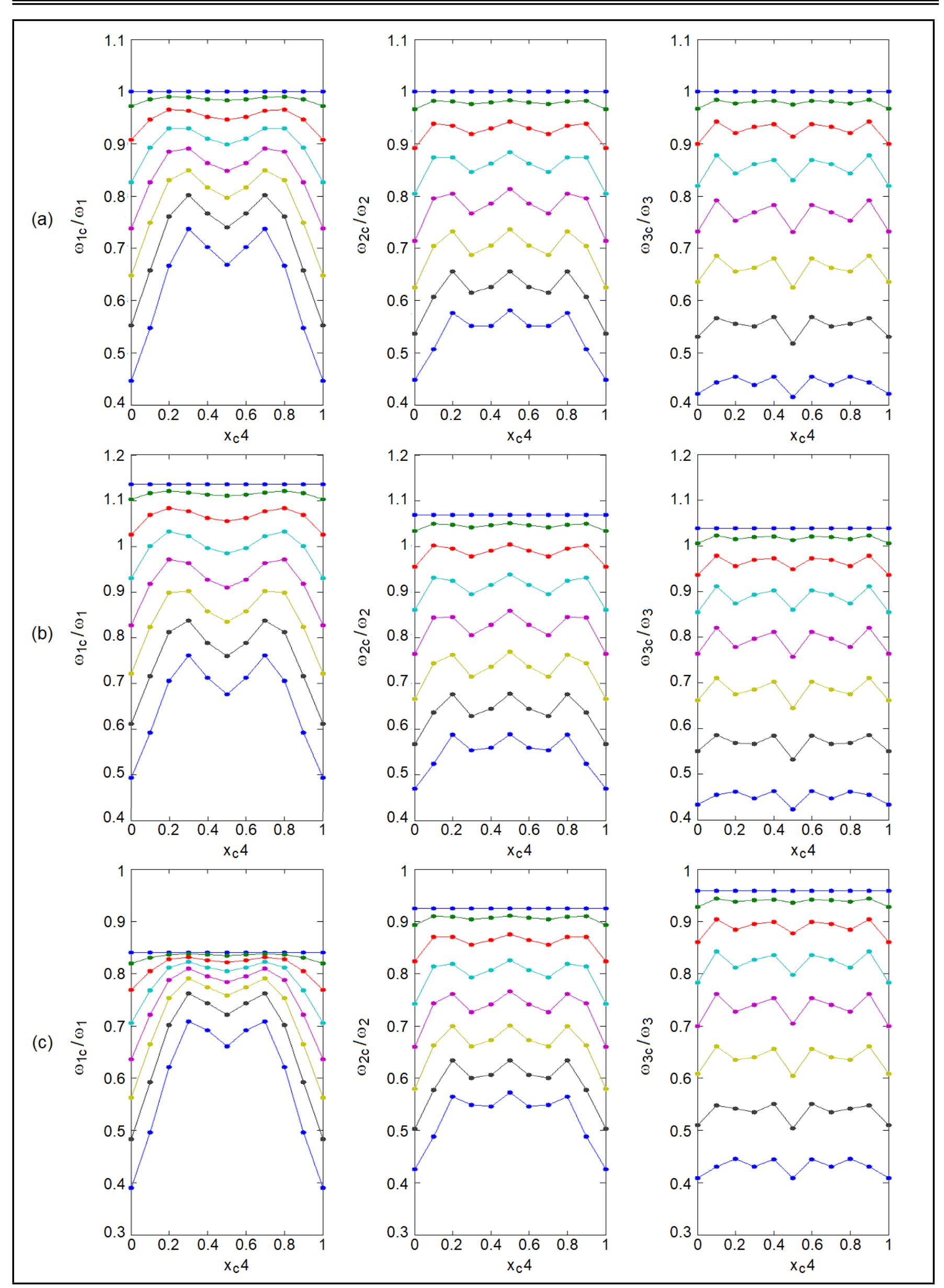

Figure 10. Same as Fig. 9, but with a fixed-fixed beam. 


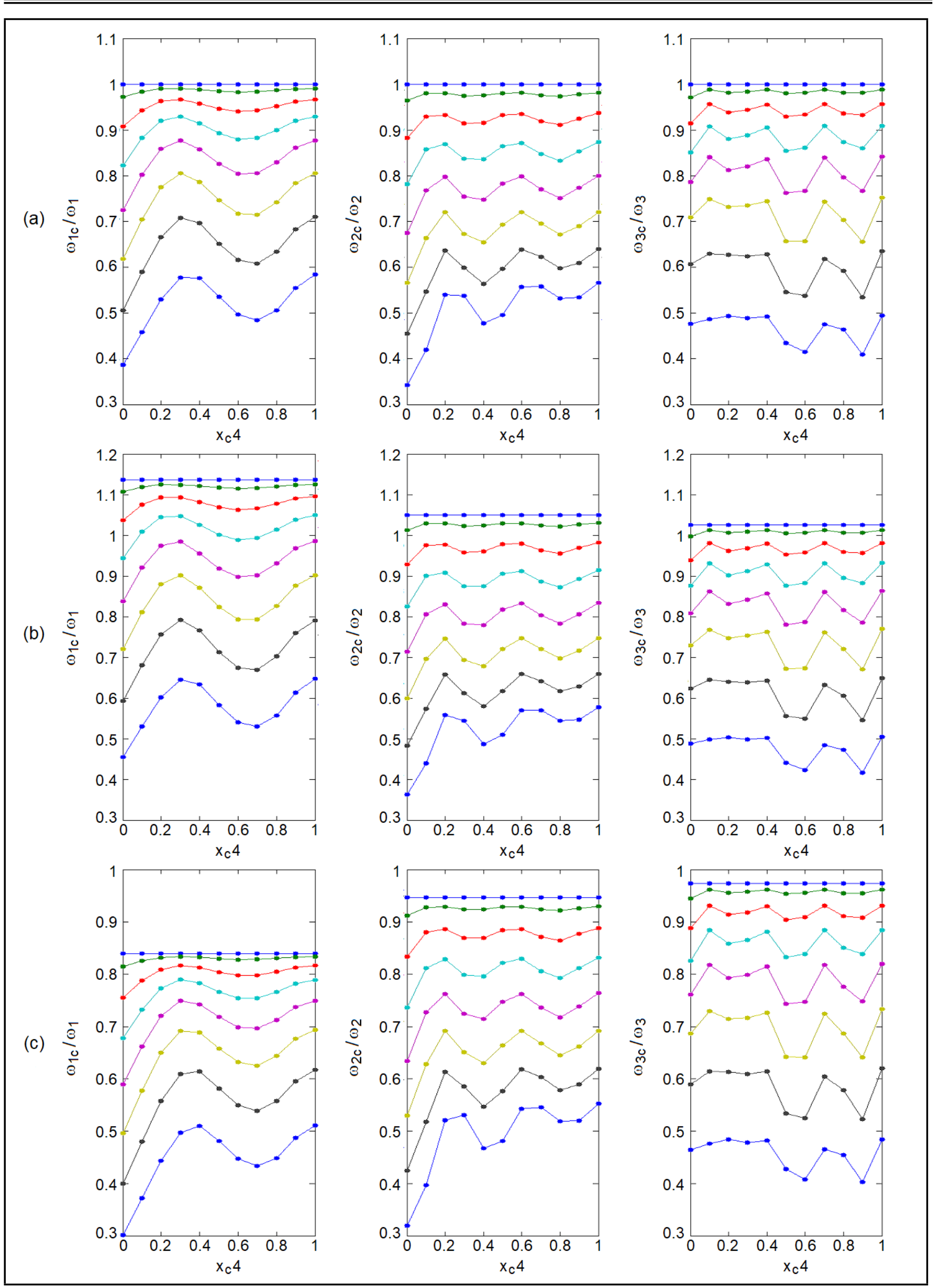

Figure 11. Same as Fig. 9, but with a fixed-hinged beam. 


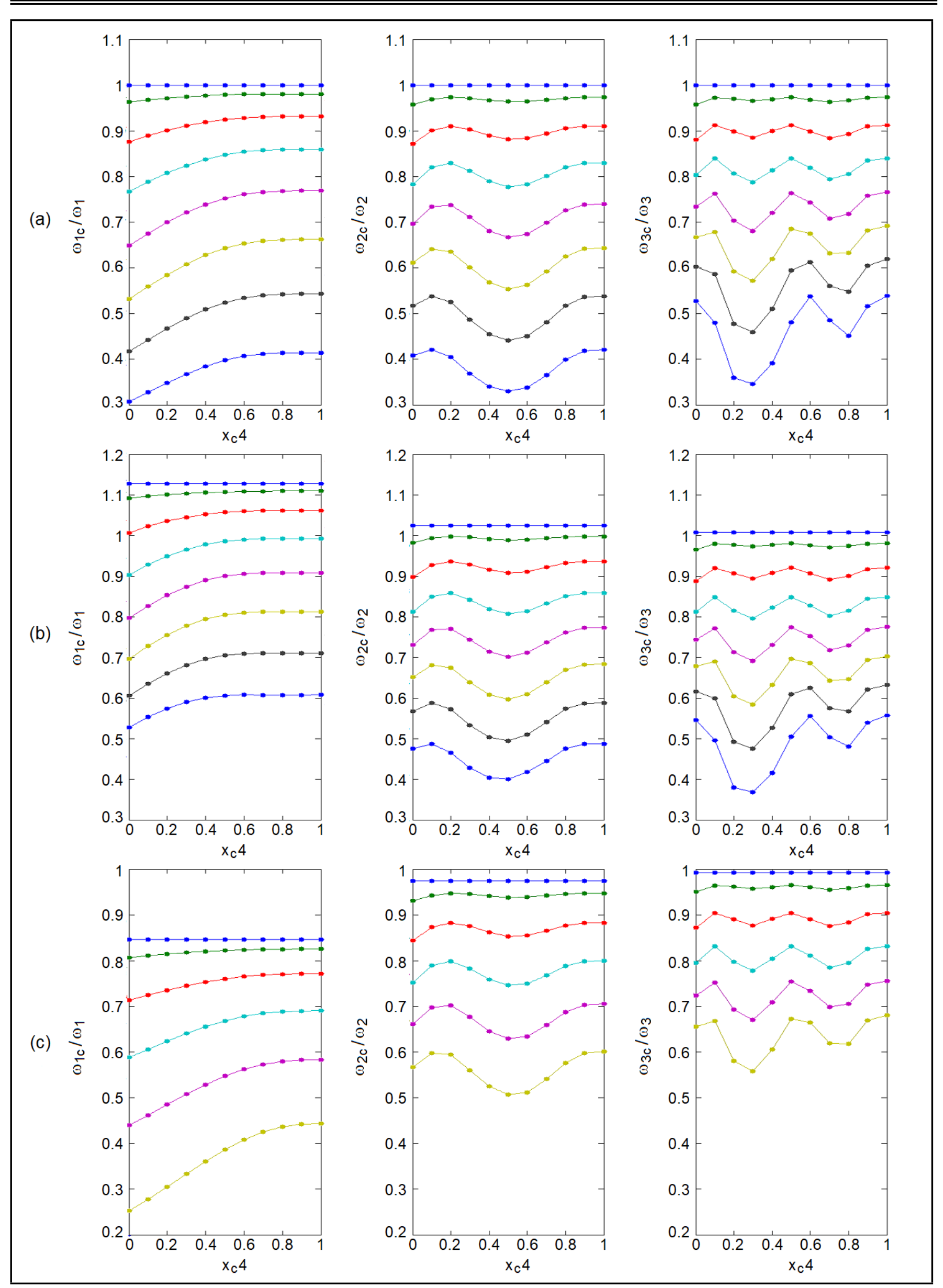

Figure 12. Same as Fig. 9, but with a fixed-free beam beam and values of $a / h: 0,0.1,0.2,0.3,0.4$, and 0.5 for (c). 


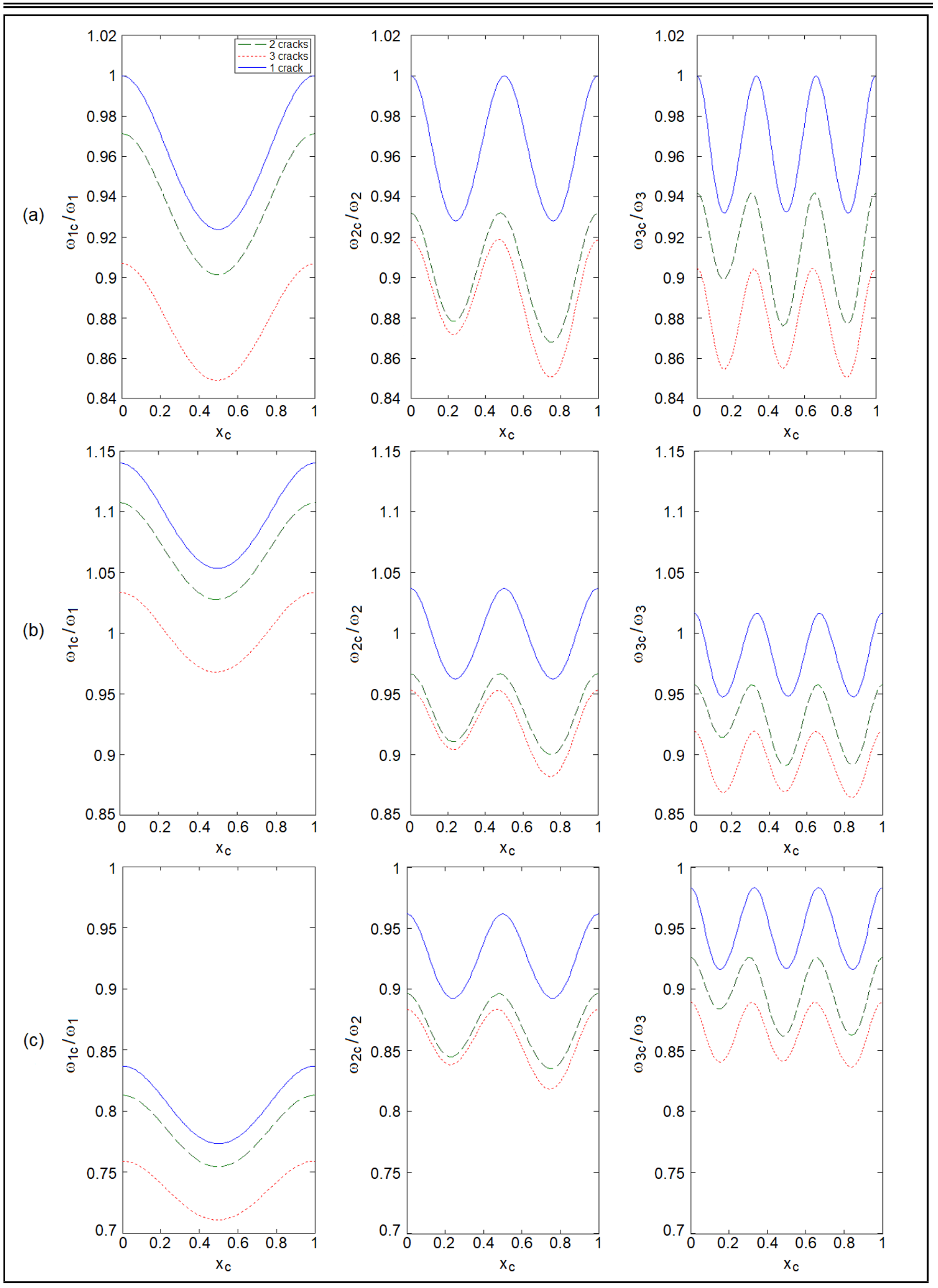

Figure 13. Effects of number of cracks on the first three non-dimensional natural frequencies of hinged-hinged beam for (a) $P / P_{c r}=0,(\mathrm{~b}) P / P_{c r}=-0.3$, and (c) $P / P_{c r}=0.3$. 


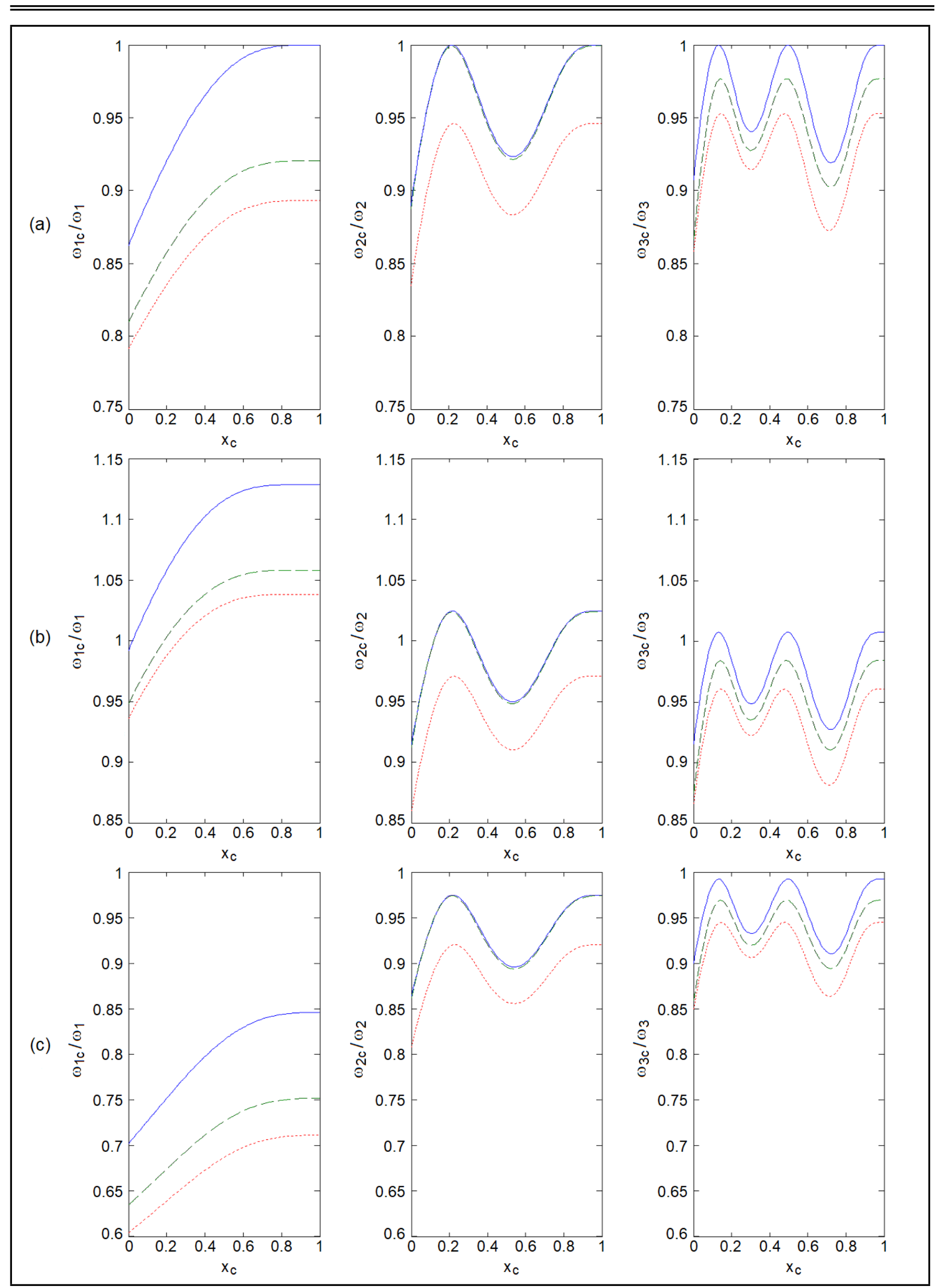

Figure 14. Same as Fig. 13, but with a fixed-free beam. 


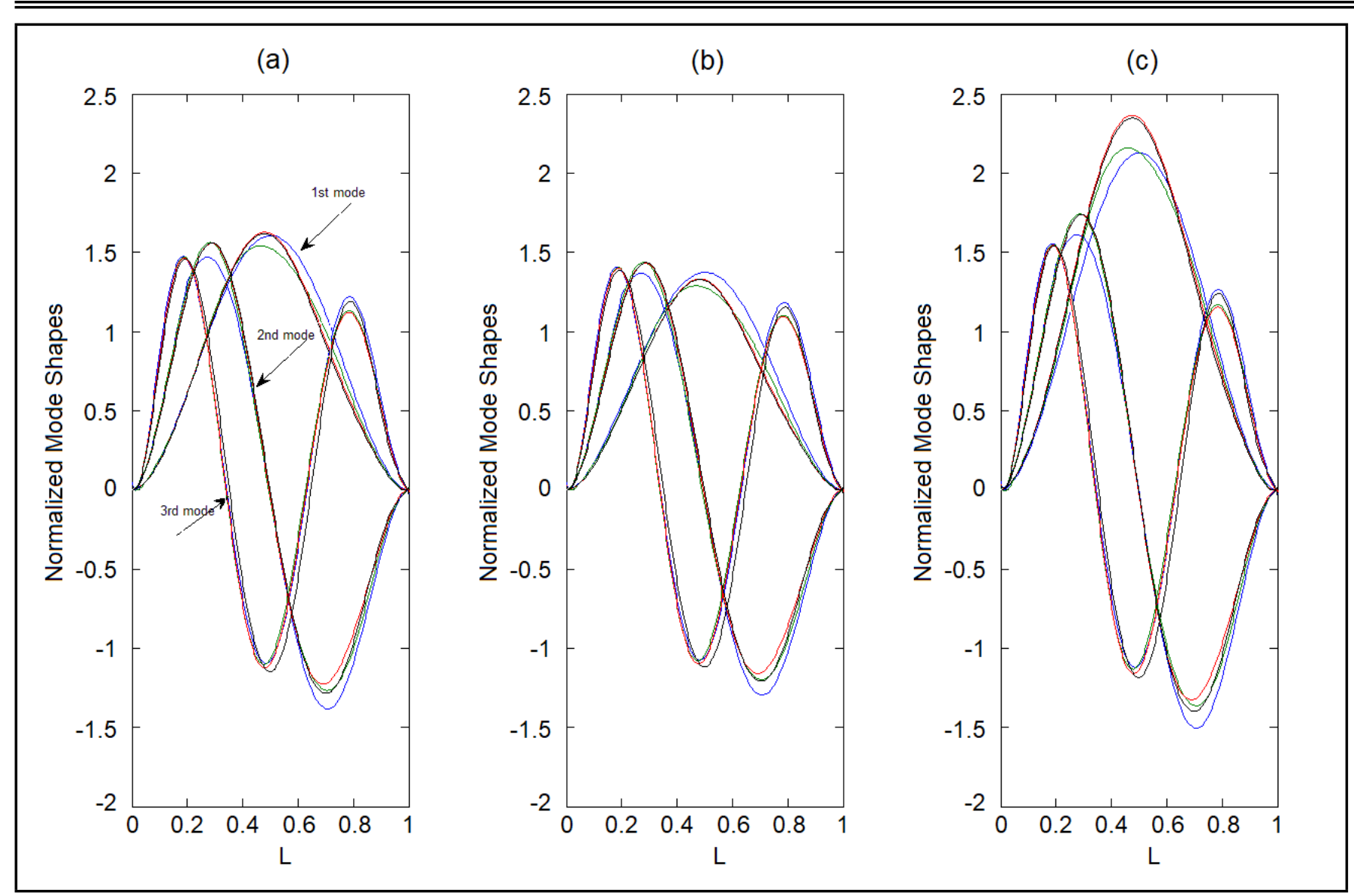

Figure 15. Effects of number of cracks on the first three mode shapes of fixed-fixed beam for (a) $P / P_{c r}=0$, (b) $P / P_{c r}=-0.3$, and (c) $P / P_{c r}=0.3$. (Blue line represents one crack, green line represents two cracks, red line represents three cracks, and black line represents four cracks.)

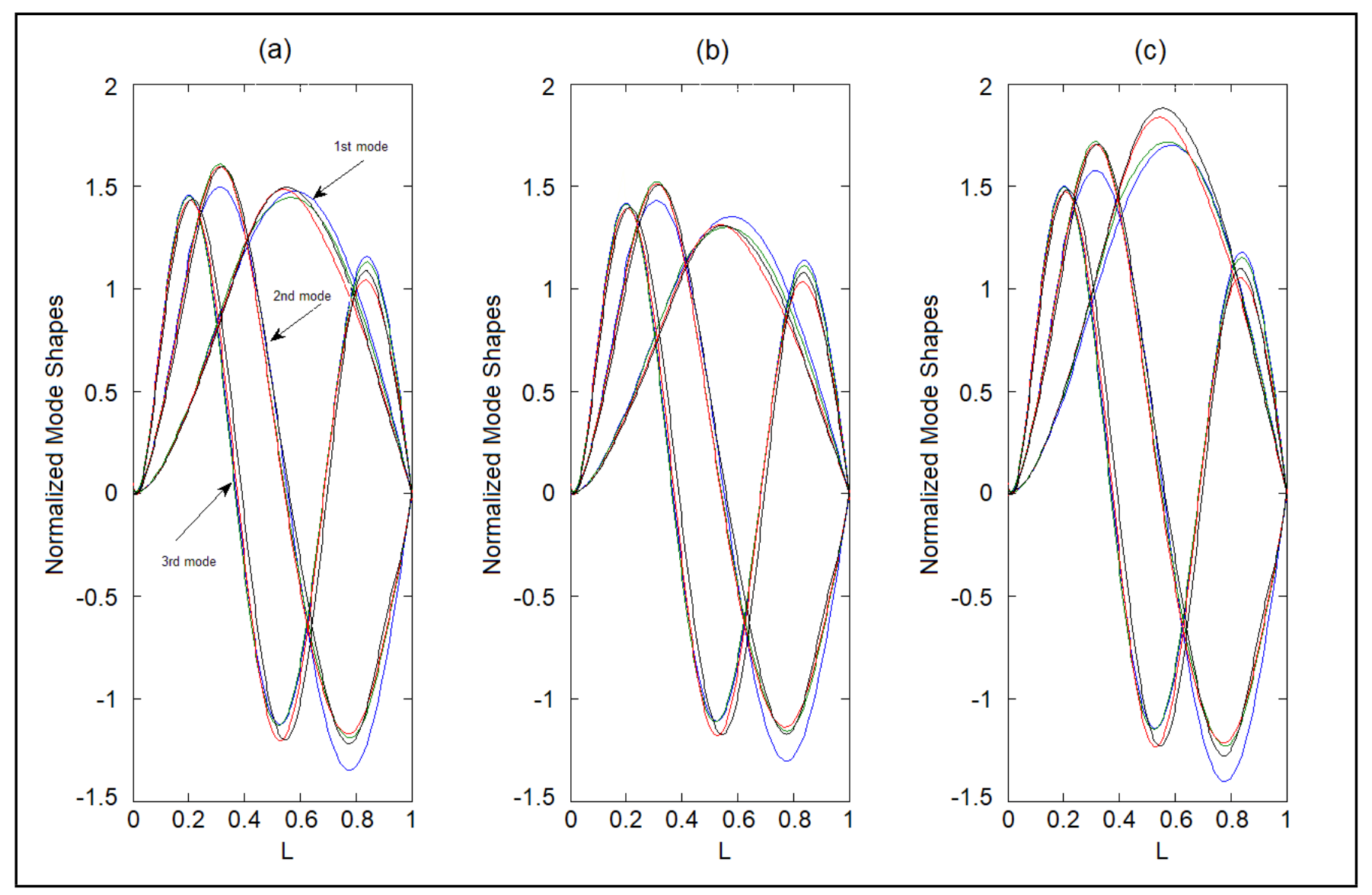

Figure 16. Same as Fig. 15, but with a fixed-hinged beam. 
the beam. It is clear from the figures that increasing the number of cracks leads to a decrease of the non-dimensional natural frequency for all load cases. Figures 15 and 16 show the effects of number of cracks on the first three mode shapes of a beam with fixed-fixed and fixed-hinged boundaries, respectively. Again, in the two figures, $a / h=0.3$ is used, figure (a) represents $P / P_{c r}=0$, figure (b) represents $P / P_{c r}=-0.3$, and figure (c) represents $P / P_{c r}=0.3$. It is clear from the figures that the number of cracks only slightly affects the mode shapes.

\section{CONCLUSIONS}

The dynamic behaviour of axially loaded Euler-Bernoulli beams with differing boundary conditions is studied using the simple transfer matrix method. The effects of axial loadings, aspect ratio, a/h, boundary conditions, and number of cracks on the non-dimensional natural frequencies and the corresponding mode shapes are investigated. The following conclusions can be drawn:

1. The compressive force softens the beam, while the tensile force stiffens the beam.

2. The severity of the cracks and the magnitude of the axial load affect the non-dimensional frequencies, especially those of the first mode.

3. As the number of cracks increases, an increase in the flexibility of the beam leads to a decrease of the natural frequency.

4. As the aspect ratio, $a / h$, increases, the natural frequency of the beam decreases for the specific crack location.

5. The natural frequencies do not change with different values of aspect ratio $(a / h)$ at the location of the zerocrossing of the mode shape and at certain locations in the beam which are called critical points.

6. The tensile force shifts the locations of critical points, for the first non-dimensional frequencies, toward the supports. The compressive force shifts them toward the centre of the beam for fixed-fixed and fixed-hinged boundaries.

7. The first cracked natural frequency is higher than those of the intact beam near the critical points for fixed-fixed and fixed-hinged boundaries.

\section{REFERENCES}

1 Liebowitz, H. and Claus Jr., W. D. Failure of notched columns, Engineering Fracture Mechanics, 1 (2), 379-383, (1968). https://dx.doi.org/10.1016/0013-7944(68)90010-6

2 Dimarogonas, A. D. Vibration of cracked structures: a state of the art review, Engineering Fracture Mechanics, 55 (5), 831-857, (1996). https://dx.doi.org/10.1016/00137944(94)00175-8

3 Kirmsher, P. G. The effect of discontinuity on natural frequency of beams, Proceedings of the American Society of Testing and Materials, 44, 897-904, (1944).
4 Thomson, W. J. Vibration of slender bars with discontinuities in stiffness, Journal of Applied Mechanics, 17, 203207, (1943).

5 Christides, S. and Barr, A. D. S. One-dimensional theory of cracked Bernoulli-Euler beams, International Journal of Mechanical Sciences, 26 (11-12), 639-648, (1984). https://dx.doi.org/10.1016/0020-7403(84)90017-1

6 Christides, S. and Barr, A. D. S. Torsional vibration of cracked beams of non-circular cross-section, International Journal of Mechanical Sciences, 28 (7), 473-490, (1986). https://dx.doi.org/10.1016/0020-7403(86)90067-6

7 Zheng, T. and Ji, T. Equivalent representations of beams with periodically variable cross-sections, Engineering Structures, 33 (3), 706-719, (2011). https://dx.doi.org/10.1016/j.engstruct.2010.11.007

8 Chondros, T. G., Dimarogonas, A. D., and Yao, J. A continuous cracked beam vibration theory, Journal of Sound and Vibration, 215 (1), 17-34, (1998). https://dx.doi.org/10.1006/jsvi.1998.1640

9 Dimarogonas, A. D. Vibration Engineering, West Publishers, St. Paul, (1976).

10 Liebowitz, H., Vanderveldt, H., and Harris, D. W. Carrying capacity of notched columns, International Journal of Solids and Structures, 3 (4), 489-490, IN1, 491-500, (1967). https://dx.doi.org/10.1016/0020-7683(67)90003-0

11 Okamura, H., Liu, H. W., Chu, C. S., and Liebowitz, H. A cracked column under compression, Engineering Fracture Mechanics, 1 (3), 547-564, (1969). https://dx.doi.org/10.1016/0013-7944(69)90011-3

12 Brown, W. and Srawley, J. Plane strain crack toughness testing of high strength metallic materials, ASTM Special Technical Publication, 410, (1966). https://dx.doi.org/10.1520/stp44663s

13 Tada, H., Paris, P., and Irwin, G. The stress analysis of cracks handbook, Research Corporation, St. Louis, (1985).

14 Yoon, H. I., Son, I. S., and Ahn, S. J. Free vibration analysis of Euler-Bernoulli beam with double cracks, Journal of Mechanical Science and Technology, 21 (3), 476-485, (2007). https://dx.doi.org/10.1007/bf02916309

15 Fernandez-Saez, J., Rubio, L., and Navarro, C. Approximate calculations of the fundamental frequency for bending vibrations of cracked beams, Journal of Sound and Vibration, 225 (2), 345-352, (1999). https://dx.doi.org/10.1006/jsvi.1999.2251

16 Fernandez-Saez, J. and Navarro, C. Fundamental frequency of cracked beams in bending vibrations: an analytical approach, Journal of Sound and Vibration, 256 (1), 17-31, (2002). https://dx.doi.org/10.1006/jsvi.2001.4197

17 Zhong, S. and Oyadiji, S. O. Analytical predictions of natural frequencies of cracked simply supported beams with a stationary moving mass, Journal of Sound and Vibration, 311 (1-2), 328-352, (2008). https://dx.doi.org/10.1016/j.jsv.2007.09.009 
18 Loya, J. A., Rubio, L., and Fernandez-Saez, J. Natural frequencies for bending vibrations of Timoshenko cracked beams, Journal of Sound and Vibration, 290 (3-5), 640653, (2006). https://dx.doi.org/10.1016/j.jsv.2005.04.005

19 Kato, T. A short introduction to perturbation theory for linear operators, Springer-Verlag, New York, (1982). https://dx.doi.org/10.1007/978-1-4612-5700-4

20 Jang, S. K. and Bert, C. W. Free vibration of stepped beams: higher mode frequencies and effects of steps on frequency, Journal of Sound and Vibration, 132 (1), 164-168, (1989). https://dx.doi.org/10.1016/0022-460x(89)90882-1

21 Naguleswaran, S. Vibration and stability of an EulerBernoulli beam with up to three-step changes in cross-section and in axial force, International Journal Mechanical Sciences, 45, 1563-1579, (2003). https://dx.doi.org/10.1016/j.ijmecsci.2003.09.001

22 Aydin, K. Vibratory characteristics of Euler-Bernoulli beams with an arbitrary number of cracks subjected to axial load, Journal of Vibration and Control, 14 (4), 485-510, (2008). https://dx.doi.org/10.1177/1077546307080028

23 Zheng, T., and Ji, T. An approximate method for determining the static deflection and natural frequency of a cracked beam, Journal of Sound and Vibration, 331 (11), 26542670, (2012). https://dx.doi.org/10.1016/j.jsv.2012.01.021

24 Gomes, H. M. and de Almeida, F. J. F. An analytical dynamic model for single-cracked beams including bending, axial stiffness, rotational inertia, shear deformation and coupling effects, Applied Mathematical Modelling, 38 (3), 938-948, (2014). https://dx.doi.org/10.1016/j.apm.2013.07.019

25 Ostachowicz, W. M. and Krawczuk, M. Analysis of the effect of cracks on the natural frequencies of a cantilever beam, Journal of Sound and Vibration, 150 (2), 191-201, (1991). https://dx.doi.org/10.1016/0022-460x(91)90615-q

26 Pestel, E. C. and Leckie, F. A. Matrix methods in elastomechanics, McGraw-Hill, London, (1963).

27 Takahashi, I. Vibration and stability of non-uniform cracked Timoshenko beam subjected to follower force, Computers and Structures, 71 (5), 585-591, (1999). https://dx.doi.org/10.1016/s0045-7949(98)00233-8

28 Ruotolo, R. and Surace, C. Natural frequencies of a bar with multiple cracks, Journal of Sound and Vibration, 272 (12), 301-316, (2004). https://dx.doi.org/10.1016/s0022$460 x(03) 00761-2$
29 Bilello, C. and Bergman, L. A. Vibration of damaged beams under a moving mass: theory and experimental validation, Journal of Sound and Vibration, 274 (3-5), 567-582, (2004). https://dx.doi.org/10.1016/j.jsv.2003.01.001

30 Liu, W. H. and Huang, C. C. Vibrations of a constrained beam carrying a heavy tip body, Journal of Sound and Vibration, 123 (1), 15-29, (1988). https://dx.doi.org/10.1016/s0022-460x(88)80074-9

31 Aleyaasin, M., Ebrahimi, M., and Whalley, R. Vibration analysis of distributed-lumped rotor systems, Computer Methods in Applied Mechanics and Engineering, 189 (2), 545-558, (2000). https://dx.doi.org/10.1016/s00457825(99)00308-4

32 Attar, M. A transfer matrix method for free vibration analysis and crack identification of stepped beams with multiple edge cracks and different boundary conditions, International Journal of Mechanical Sciences, 57 (1), 19-33, (2012). https://dx.doi.org/10.1016/j.ijmecsci.2012.01.010

33 Nandwana, B. P. and Maiti, S. K. Detection of the location and size of a crack in stepped cantilever beams based on measurements of natural frequencies, Journal of Sound and Vibration, 203 (3), 435-446, (1997). https://dx.doi.org/10.1006/jsvi.1996.0856

34 Khiem, N. T. and Lien, T. V. A simplified method for natural frequency analysis of a multiple cracked beam, Journal of Sound and Vibration, 245 (4), 737-751, (2001). https://dx.doi.org/10.1006/jsvi.2001.3585

35 Khiem, N. T. and Lien, T. V. The dynamic stiffness matrix method in forced vibration analysis of multiple-cracked beam, Journal of Sound and Vibration, 254 (3), 541-555, (2002). https://dx.doi.org/10.1006/jsvi.2001.4109

36 Zheng, D. Y. and Kessissoglou, N. J. Free vibration analysis of a cracked beam by finite element method, Journal of Sound and Vibration, 273 (3), 457-475, (2004). https://dx.doi.org/10.1016/S0022-460X(03)00504-2

37 Kisa, M. Vibration and stability of multi-cracked beams under compressive axial loading, International Journal of Physical Sciences, 6 (11), 2681-2696, (2011). https://dx.doi.org/10.5897/IJPS11.493

38 Nguyen, K. V., Mode shapes analysis of a cracked beam and its application for crack detection, Journal of Sound and Vibration, 333 (3), 848-872, (2014). https://dx.doi.org/10.1016/j.jsv.2013.10.006 